\title{
THE EFFECTS OF DOG WALKING ON WELL-BEING
}

\author{
A thesis submitted to \\ the Faculty of Graduate Studies and Research \\ in Partial Fulfillment of the requirements for the degree \\ Masters of Arts \\ by
}

Nikolina M. Duvall Antonacopoulos

Department of Psychology

Carleton University

January 2009

(C)2009 Nikolina M. Duvall Antonacopoulos 
Library and Archives

Published Heritage

Branch

395 Wellington Street

Ottawa ON K1A ON4

Canada
Bibliothèque et

Archives Canada

Direction du

Patrimoine de l'édition

395 , rue Wellington

Ottawa ON K1A ON4

Canada
Your file Votre référence

ISBN: 978-0-494-68658-4

Our file Notre reférence

ISBN: 978-0-494-68658-4
NOTICE:

The author has granted a nonexclusive license allowing Library and Archives Canada to reproduce, publish, archive, preserve, conserve, communicate to the public by telecommunication or on the Internet, loan, distribute and sell theses worldwide, for commercial or noncommercial purposes, in microform, paper, electronic and/or any other formats.

The author retains copyright ownership and moral rights in this thesis. Neither the thesis nor substantial extracts from it may be printed or otherwise reproduced without the author's permission.
AVIS:

L'auteur a accordé une licence non exclusive permettant à la Bibliothèque et Archives Canada de reproduire, publier, archiver, sauvegarder, conserver, transmettre au public par télécommunication ou par l'Internet, prêter, distribuer et vendre des thèses partout dans le monde, à des fins commerciales ou autres, sur support microforme, papier, électronique et/ou autres formats.

L'auteur conserve la propriété du droit d'auteur et des droits moraux qui protège cette thèse. $\mathrm{Ni}$ la thèse ni des extraits substantiels de celle-ci ne doivent être imprimés ou autrement reproduits sans son autorisation.
In compliance with the Canadian Privacy Act some supporting forms may have been removed from this thesis.

While these forms may be included in the document page count, their removal does not represent any loss of content from the thesis.
Conformément à la loi canadienne sur la protection de la vie privée, quelques formulaires secondaires ont été enlevés de cette thèse.

Bien que ces formulaires aient inclus dans la pagination, il n'y aura aucun contenu manquant. 


\begin{abstract}
While studies have found that dog ownership is beneficial for people's health, few studies (Lacey, 2004; Serpell, 1991; Thorpe et al., 2006b) have examined the effects of dog walking on people's well-being and these studies have not compared the health of dog owners who do and do not walk their dog. The present study was therefore designed to compare the physical activity and health of people who walked their dog, people who walked their dog minimally or not at all, and people who did not own a dog. The present study also examined whether, as time spent dog walking increased, there was a corresponding improvement in health. A sample consisting of 658 Canadian dog owners (79.5\% female) and non-owners completed a survey containing measures of their physical activity, physical health and psychological health. Planned comparisons revealed that, while dog walkers engaged in more physical activity than both non-owners and dog owners who walked their dog minimally or not at all, non-owners had better physical health than both groups and did not differ in their psychological health from either group. In addition, dog walkers engaged in more physical activity and had better physical health than dog owners who walked their dog minimally or not at all. Finally, hierarchical regression analyses revealed that, as the amount of time dog walkers spent dog walking increased, their physical and psychological health improved. That the health benefits of dog ownership appear to depend on whether a dog is walked and for how long highlight the heterogeneous nature of dog owners. The strengths and limitations of this research are discussed, as are the research-related and applied implications of these findings.
\end{abstract}




\section{Acknowledgements}

I would like to express my gratitude to a number of people. I am grateful to Dr. Connie Kristiansen for her guidance, insight, and unwavering enthusiasm for my topic. I would also like to thank my committee members: Dr. Frank Elgar, Dr. George Pollard and Dr. Timothy Pychyl for their helpful comments and interest in my research. In addition, I am grateful to Dr. Bruce Hutcheon for his helpful advice regarding my analyses. I would also like to thank friends who provided support in various ways; without your assistance my study would not have been possible (Kelly Christie, Mandy Dingsdale, Leith Higdon, Kathleen Hughes, Melanie Oattes and Beatrice Scholten). I am indebted to my family for their support and for keeping me calm. Finally, I owe a tremendous thanks to Ernest (my adorable standard poodle) who inspired me to conduct research on the benefits of pet ownership. He made writing my thesis a positive experience by constantly sitting by my side. 


\section{Table of Contents}

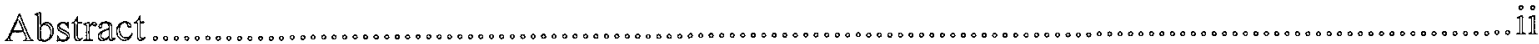

Acknowledgements........................................................................................................ii

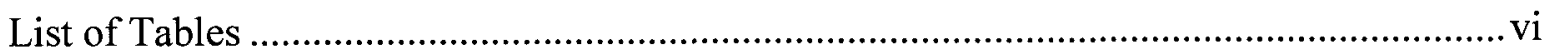

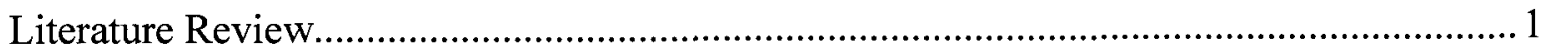

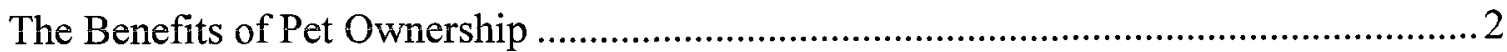

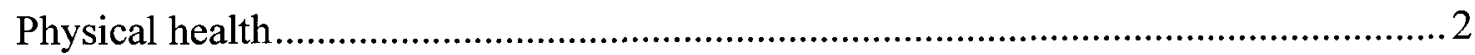

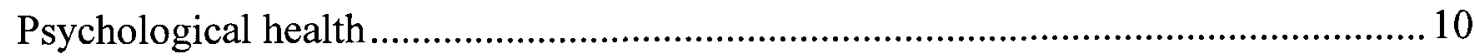

The Relationship between Dog Walking and Well-Being ................................................ 16

Dog ownership, walking and total physical activity ..................................................... 17

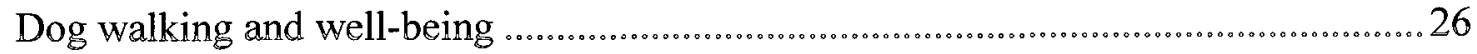

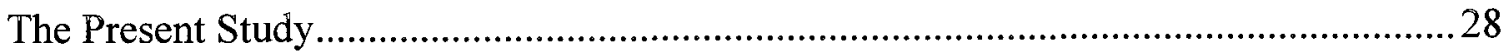

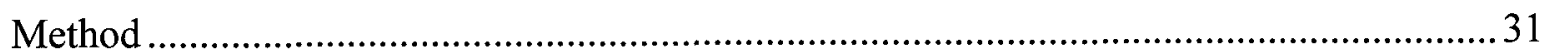

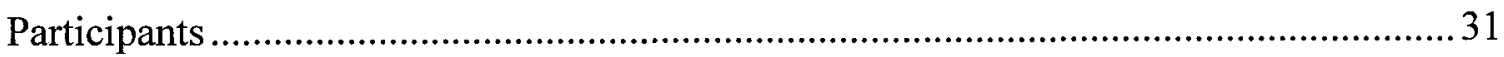

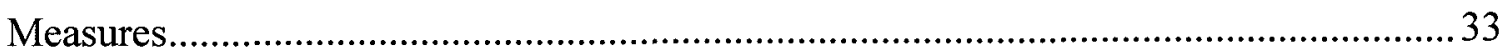

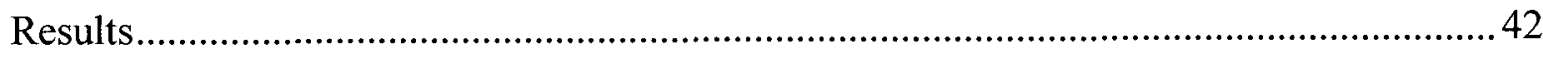

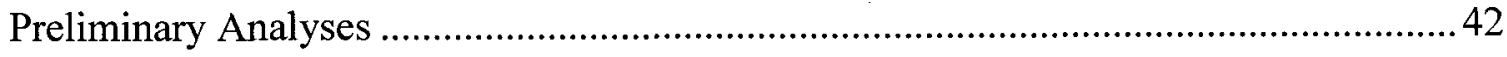

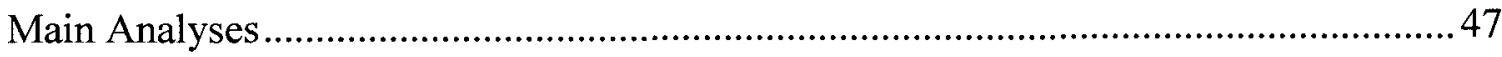

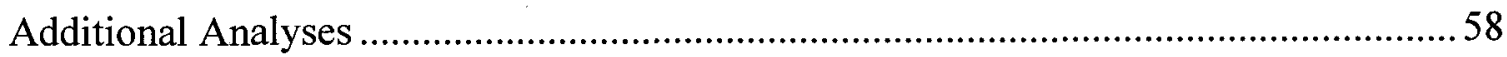

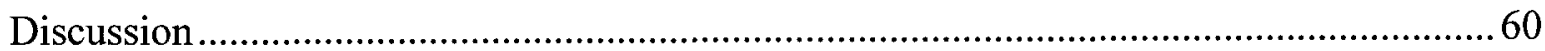

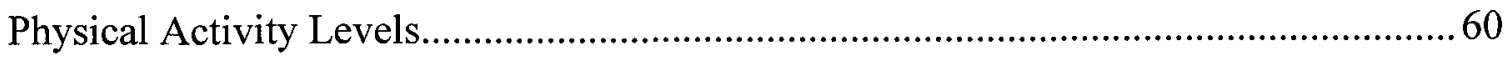

Physical and Psychological Health ..................................................................................63

Dog Walkers' Physical and Psychological Health ............................................................67

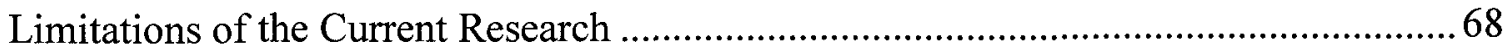




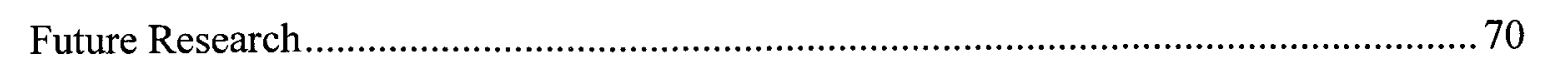

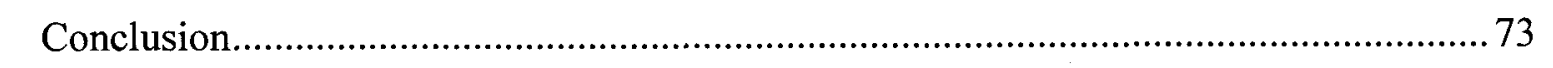

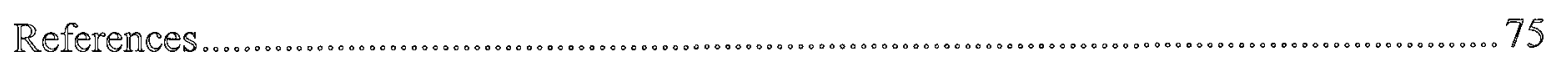

Appendix A: Research Materials . ... . . . ............................................................. 86 


\section{List of Tables}

Table 1: Longitudinal Studies of the Relationship between Pet Ownership

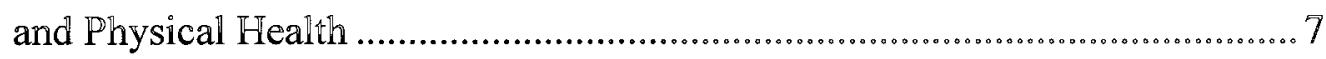

Table 2: $\quad$ Cross-Sectional Studies of the Relationship between Pet Ownership

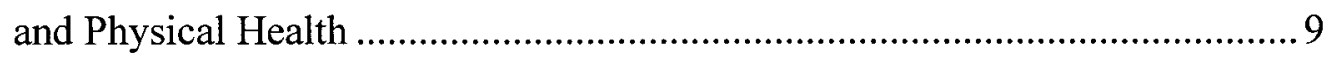

Table 3: $\quad$ Studies of the Relationship between Pet Ownership and Psychological

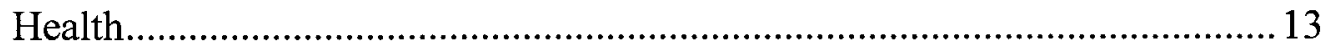

Table 4: $\quad$ Studies of Walking by People Who Do and Do Not Own a Dog................. 18

Table 5: $\quad$ Studies of the Total Physical Activity of People Who

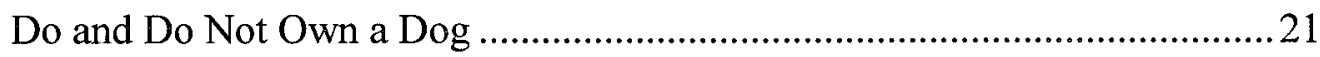

Table 6: $\quad$ Percentage of Dog Owners Who Do Not Walk Their Dog ..........................23

Table 7: Studies of Walking and Total Physical Activity by People Who

Walk Their Dog, Do Not Walk Their Dog or Do Not Own a Dog ................225

Table 8: Correlations and Descriptive Statistics for the Measures of

Physical Health (Untransformed) .............................................. 43

Table 9: Results of Item Analyses and Descriptive Statistics for the

Measures of Psychological Health (Untransformed)................................. 44

Table 10: Descriptive Statistics and Correlations between the Predictor and

Criterion Activity Measures (Untransformed) .................................... 45

Table 11: Results of Item Analyses and Descriptive Statistics for

Potential Covariates ........................................................................... 47

Table 12: Results of the Hierarchical Regression of the Physical Health of Dog

Owners Who Walk Their Dogs $(n=460)$ onto Covariates and Minutes

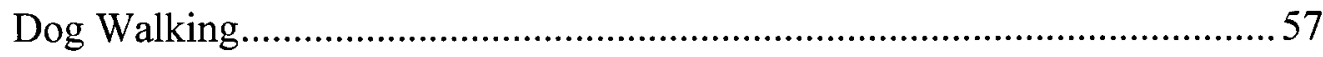


Table 13: Results of the Hierarchical Regression of the $\mathbb{P}$ sychological Health of Dog Owners Who Walk Their Dogs $(n=451)$ onto Covariates and Minutes

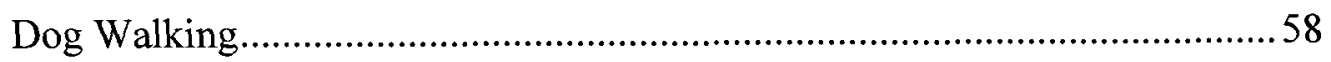


More than hallf of North American households have a pet, with dogs being the most popular (American Pet Products Manufacturers Association, 2008; Leger Marketing, 2002). Dogs are unique because, unlike other household pets, they require exercise; therefore, it is likely that dog owners receive health benefits from the physical activity they obtain walking their dogs. In this regard, researchers have found that physical activity is associated with physical and psychological health benefits (Gilmour, 2007; U.S. Department of Health and Human Services, 1996). With respect to physical health, for example, greater physical activity lowers blood pressure and reduces overall mortality rates and the likelihood of being overweight or obese (Gilmour, 2007; U.S. Department of Health and Human Services, 1996). It also reduces the risk of cardiovascular diseases (e.g., coronary heart disease), type 2-diabetes, osteoporosis, osteoarthritis and some forms of cancer. With respect to psychological health, increased physical activity contributes to positive affect and general well-being and reduces depression, anxiety and stress (Gilmour, 2007; U.S. Department of Health and Human Services, 1996).

The physical inactivity of Canadians is a concern given the findings of Statistics Canada's 2005 Canadian Community Health Survey, which indicated that $48 \%$ of Canadians age 12 and over did not receive sufficient amounts of physical activity (Gilmour, 2007). Further, in 2001 physical inactivity in Canada resulted in health care costs of approximately 5.3 billion dollars (Katzmarkzyk \& Janssen, 2004). In light of these figures, the potential health benefits of dog walking merit attention. 
Dog Walking and Well-Being 2

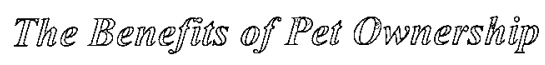

Using both longitudinal and cross-sectional designs, researchers have found that pet ownership is beneficial for physical and psychological health.

Physical health. At least eight longitudinal and seven cross-sectional studies, summarized in Tables 1 and 2, have examined the relationship between pet ownership and physical well-being. In one of the longitudinal studies, conducted in the United Kingdom by Serpell (1991), 47 people who acquired a dog experienced fewer minor health problems 1 month after they acquired a dog, a reduction that was maintained at both 6 and 10 months. In contrast, a control group of 26 people without a dog did not experience a significant change in the number of minor health problems they experienced over the course of the 10-month study.

Another longitudinal study, involving survey data from 9,721 people in Germany, was designed to determine whether people become healthier after they acquire their pets or whether healthier people acquire pets. The authors of this study (Headey \& Grabka, 2007) found that people who continuously owned a pet (typically a dog or cat) throughout the study (from 1996 to 2001) made fewer doctor visits in 2001, relative to people who stopped being a pet owner at some point during the study and people who did not own a pet throughout the study. In addition, people who did not own a pet in 1996, but then acquired a pet at some point during the study, made fewer doctor visits in 2001 compared to people who did not own a pet over the course of the study. Finally, people who owned a pet in 2001 made $7.5 \%$ fewer doctor visits in the previous year than people who did not own a pet in 2001. Given these findings, Headey and Grabka concluded that 
people's health improves following the acquisition of a pet.

Cross-sectional studies have also provided evidence of the link between pet ownership and physical health. In their retrospective survey of 1,246 Australians, Headey and Grabka (2007) found that those who owned a pet (usually a dog or cat) in both 1996 and 2001 made fewer doctor visits in 2001, compared to both individuals who owned a pet in 1996, but not 2001, and individuals without a pet at both times.

Surprisingly, however, people who owned a pet in 2001, but not in 1996, and people who did not own a pet at either time did not differ in the number of doctor visits they made in 2001. Finally, they found that individuals who owned a pet in 2001 made $11 \%$ fewer doctor visits in the previous year than individuals who did not own a pet in 2001. In an earlier cross-sectional survey of 1,011 Australians, Headey (1999) found that people who owned a dog, but not a cat, took less medication for heart and sleeping problems in the past year than people without a dog or cat. In addition, in a study of 3,031 Chinese women 25 to 40 years of age, women who owned a dog reported fewer doctor visits in the past 3 months than women without a dog (Headey, Na, \& Zheng, 2007). Dog owners also reported feeling more physically fit, having better health, sleeping better in the past month and missing fewer days of work due to illness in the past year than women without a dog.

Other research has documented health-related physiological benefits for pet owners. Odendaal (2000), for example, found that interacting with a pet dog reduced cortisol levels and increased $\beta$-endorphin, oxytocin, prolactin, phenylacetic acid, and dopamine levels, neurochemicals associated with lower blood pressure. Similarly, in a 
study of risk factors linked to cardiovascular disease in a sample of individuals 20 to 59 years of age, pet owners $(n=784)$ had lower systolic blood pressure and plasma triglyceride levels relative to people without a pet $(n=4,957$; Anderson, Reid, \& Jennings, 1992). When participants' gender was considered, this difference held for men's systolic blood pressure and plasma triglycerides levels. Male pet owners 20 to 59 years of age also had lower plasma cholesterol levels compared to males without a pet. However, the benefits of pet ownership were far less pronounced among women, with the only difference being the lower systolic blood pressure of women 40 to 59 years of age who owned a pet relative to those who did not. The researchers suggested that pet ownership may have had little impact on the cardiovascular risk factors of women 20 to 39 years of age because cardiovascular disease only becomes a leading cause of women's death after the age of 40 .

Researchers have also documented the benefits of pet ownership for people suffering from cardiovascular disease. In a longitudinal study of 92 patients discharged from a coronary care unit with a diagnosis of myocardial infarction or angina pectoris, Friedmann, Katcher, Lynch, and Thomas (1980) found that pet owners were less likely to die during the year following discharge than those who did not own pets. Friedmann and Thomas (1995) subsequently replicated this study with a larger sample of 369 postmyocardial infarction patients with ventricular arrhythmias. Although pet owners, primarily of dogs and cats, were more likely to be alive 1 year later, when they considered the type of pet only dog owners were more likely to be alive at the end of the study. Based on other research, Friedmann and Thomas suggested that this finding may 
have occurred because dog owners are less sedentary than cat owners. Fimally, in a study of 81 patients participating in a 12-week cardiac rehabilitation program, Herrald, Tomaka, and Medina (2002) found that pet owners (of primarily dogs and cats) were more likely than people without a pet to complete the program. This suggests that participation in rehabilitation may account for the greater longevity of pet owners suffering from cardiovascular disease.

Longitudinal studies have also documented the salutary physical health benefits of pet ownership among community residing elders. A 1-year study of 995 seniors found less deterioration in the physical health of those who owned a dog or cat relative to those who did not own a pet, as indicated by differences in seniors' ability to perform daily activities such as bathing, dressing and preparing meals for themselves (Raina, WaltnerToews, Bonnett, Woodward, \& Abernathy, 1999). Similarly, in Siegel's (1990) year-long study of 938 elders, those who owned a pet (usually a dog or cat) reported fewer doctor contacts than elders who did not own a pet. Siegel also found that elders without a pet who experienced more stressful life events in the six months prior to the study had more doctor contacts throughout the study compared to those who experienced fewer stressful life events. In contrast, the number of stressful life events did not affect how often dog owners contacted a doctor. This finding suggests that dog ownership may buffer the negative effects of stress. Finally, a 110-month study of 2,799 seniors observed that pet ownership was beneficial for women but not men. Specifically, while female seniors who owned a pet were $28 \%$ less likely to be hospitalized at 110 months compared to female seniors without a pet, hospitalization was independent of senior males' pet 
ownership (Simons, Simons, McCallum, \& Friedlander, 2000).

Cross-sectional studies of seniors have found links between pet ownership and physical health comparable to those observed in both longitudinal studies of seniors and studies of younger adults. For example, seniors who own a pet (primarily a dog or cat) have been found to have lower serum triglyceride levels relative to those who do not own a pet (Dembicki \& Anderson, 1996). In addition, seniors who own a dog have been found to describe their general health as better now than 5 years earlier and report fewer sick days in the past 6 months compared to seniors without a dog (Rogers, Hart, \& Boltz, 1993).

Taken together, these longitudinal and cross-sectional studies suggest that pet owners, particularly dog owners, are healthier than people who do not own pets in that they take less medication (Headey, 1999), have fewer doctor visits (Headey \& Grabka, 2007; Headey et al., 2007; Siegel, 1990), have fewer sick days (Headey et al., 2007; Rogers et al., 1993), sleep better (Headey et al., 2007) and rate their health as better (Headey et al., 2007; Rogers et al., 1993). Not only does pet ownership provide cardiovascular health benefits (Anderson et al., 1992), but pet owners recovering from cardiovascular disease appear to fare better than people without a pet (Friedmann et al., 1980; Friedmann \& Thomas, 1995; Herrald et al., 2002). The consistency of the findings of these studies, using different methods (i.e., longitudinal vs. cross-sectional) with different populations (i.e., members of the general population, women and seniors living in the United Kingdom, the United States, Canada, Germany, Australia, China and South Africa) and examining different indices of physical well-being (e.g., self-reports of 
health-related behaviours vs. physiological measures) provide convincing evidence that pets, especially dogs, provide salutary physical health benefits to their owners.

Table 1.

Longitudinal Studies of the Relationship between Pet Ownership and Physical Health

\begin{tabular}{|c|c|c|c|}
\hline Researchers & Sample \& study design & Measures & Results \\
\hline $\begin{array}{l}\text { Friedmann et } \\
\text { al. (1980) }\end{array}$ & $\begin{array}{l}\text { Americans who did }(n=53) \\
\text { and did not }(n=39) \text { own a } \\
\text { pet were followed for } 1 \text { year } \\
\text { after discharge from a } \\
\text { coronary care unit }\end{array}$ & $\begin{array}{l}\text { Survival at the } \\
\text { end of the year }\end{array}$ & $\begin{array}{l}\text { Pet owners were more } \\
\text { likely to be alive than non- } \\
\text { owners. }\end{array}$ \\
\hline $\begin{array}{l}\text { Friedmann et } \\
\text { al. (1995) }\end{array}$ & $\begin{array}{l}\text { American and Canadian } \\
\text { post-myocardial infarction } \\
\text { patients who did }(n=87) \\
\text { and did not }(n=262) \text { own a } \\
\text { dog were followed for } 1 \\
\text { year }\end{array}$ & $\begin{array}{l}\text { Survival at the } \\
\text { end of the year }\end{array}$ & $\begin{array}{l}\text { Dog owners were more } \\
\text { likely to be alive than non- } \\
\text { owners. }\end{array}$ \\
\hline $\begin{array}{l}\text { Headey and } \\
\text { Grabka } \\
(2007)\end{array}$ & $\begin{array}{l}9,721 \text { German pet owners } \\
\text { and non-owners were } \\
\text { followed from } 1996 \text { to } 2001\end{array}$ & $\begin{array}{l}\text { Number of } \\
\text { annual doctor } \\
\text { visits in } 2001\end{array}$ & $\begin{array}{l}\text { Pet owners over the entire } \\
\text { study had fewer doctor } \\
\text { visits than people who } \\
\text { ceased to own pets and } \\
\text { non-owners. People who } \\
\text { became pet owners during } \\
\text { the study had fewer doctor } \\
\text { visits than non-owners. }\end{array}$ \\
\hline $\begin{array}{l}\text { Herrald et al. } \\
(2002)\end{array}$ & $\begin{array}{l}\text { American outpatients who } \\
\text { did }(n=56) \text { and did not } \\
(n=25) \text { own a pet took part } \\
\text { in a 12-week cardiac } \\
\text { rehabilitation program }\end{array}$ & $\begin{array}{l}\text { Completion of } \\
\text { cardiac } \\
\text { rehabilitation } \\
\text { program }\end{array}$ & $\begin{array}{l}\text { Pet owners were more } \\
\text { likely to complete the } \\
\text { program than non-owners. }\end{array}$ \\
\hline
\end{tabular}


Table 1. cont $^{9} d$.

Longitudinal Studies of the Relationship between Pet Ownership and Physical Health

\begin{tabular}{|c|c|c|c|}
\hline Researchers & Sample \& study design & Measures & Results \\
\hline $\begin{array}{l}\text { Raina et al. } \\
\text { (1999) }\end{array}$ & $\begin{array}{l}995 \text { Canadian senior dog or } \\
\text { cat owners and non-owners } \\
\text { were followed for } 1 \text { year }\end{array}$ & $\begin{array}{l}\text { Activities of } \\
\text { Daily Living } \\
\text { scale }\end{array}$ & $\begin{array}{l}\text { Seniors pet owners had less } \\
\text { deterioration in their } \\
\text { physical health over the } \\
\text { year than senior non- } \\
\text { owners. }\end{array}$ \\
\hline Siegel (1990) & $\begin{array}{l}\text { American seniors who did } \\
(n=593) \text { and did not } \\
(n=345) \text { own a pet were } \\
\text { followed for } 1 \text { year }\end{array}$ & $\begin{array}{l}\text { Doctor } \\
\text { contacts in } \\
\text { previous year }\end{array}$ & $\begin{array}{l}\text { Senior pet owners made } \\
\text { fewer doctor contacts than } \\
\text { senior non-owners. }\end{array}$ \\
\hline $\begin{array}{l}\text { Serpell } \\
(1991)\end{array}$ & $\begin{array}{l}47 \text { people in the United } \\
\text { Kingdom who acquired a } \\
\text { dog and a control group of } \\
26 \text { non-owners were } \\
\text { followed for } 10 \text { months }\end{array}$ & $\begin{array}{l}\text { Number of } \\
\text { minor health } \\
\text { complaints in } \\
\text { previous } \\
\text { month }\end{array}$ & $\begin{array}{l}\text { Dog owners had fewer } \\
\text { minor health complaints at } \\
1 \text { month and this effect } \\
\text { persisted } 6 \text { and } 10 \text { months } \\
\text { after acquiring a dog. No } \\
\text { significant changes for the } \\
\text { control group. }\end{array}$ \\
\hline $\begin{array}{l}\text { Simons et al. } \\
(2000)\end{array}$ & $\begin{array}{l}\text { Australian seniors who did } \\
(n=1,298) \text { and did not } \\
(n=1,501) \text { own a pet were } \\
\text { followed for } 110 \text { months }\end{array}$ & Hospitalization & $\begin{array}{l}\text { Among females, pet } \\
\text { owners were less likely } \\
\text { than non-owners to be } \\
\text { hospitalized at } 110 \text { months. } \\
\text { No significant difference } \\
\text { for elderly males. }\end{array}$ \\
\hline
\end{tabular}


Table 2.

Cross-Sectional Studies of the Relationship between Pet Ownership and Physical

Health

\begin{tabular}{|c|c|c|c|}
\hline Researchers & Sample & Measures & Results \\
\hline $\begin{array}{l}\text { Anderson et } \\
\text { al. (1992) }\end{array}$ & $\begin{array}{l}\text { Australians who did } \\
(n=784) \text { and did not } \\
(n=4,957) \text { own a pet }\end{array}$ & $\begin{array}{l}\text { Risk factors } \\
\text { for } \\
\text { cardiovascular } \\
\text { disease }\end{array}$ & $\begin{array}{l}\text { Pet owners had lower } \\
\text { systolic blood pressure and } \\
\text { plasma triglyceride levels } \\
\text { than non-owners. }\end{array}$ \\
\hline $\begin{array}{l}\text { Dembicki } \\
\text { and Anderson } \\
(1996)\end{array}$ & $\begin{array}{l}\text { American seniors who did } \\
(n=44) \text { and did not }(n=83) \\
\text { own a pet }\end{array}$ & $\begin{array}{l}\text { Serum } \\
\text { triglyceride } \\
\text { levels }\end{array}$ & $\begin{array}{l}\text { Senior pet owners had } \\
\text { lower serum triglyceride } \\
\text { levels than senior non- } \\
\text { owners. }\end{array}$ \\
\hline $\begin{array}{l}\text { Headey } \\
(1999)\end{array}$ & $\begin{array}{l}1,011 \text { Australians who did } \\
\text { or did not own a dog or cat }\end{array}$ & $\begin{array}{l}\text { Medication, } \\
\text { taken in past } \\
\text { year, for heart } \\
\text { and sleeping } \\
\text { problems }\end{array}$ & $\begin{array}{l}\text { Adults who owned a dog } \\
\text { used less medication. }\end{array}$ \\
\hline $\begin{array}{l}\text { Headey and } \\
\text { Grabka } \\
(2007)\end{array}$ & $\begin{array}{l}\text { Five year retrospective } \\
\text { study (1996 to 2001) of } \\
1,246 \text { Australians who did } \\
\text { or did not own a pet }\end{array}$ & $\begin{array}{l}\text { Number of } \\
\text { annual doctor } \\
\text { visits in } 2001\end{array}$ & $\begin{array}{l}\text { People who owned pets } \\
\text { over the } 5 \text { years had fewer } \\
\text { doctor visits than people } \\
\text { who only owned pets in } \\
2001 \text { and non-owners. } \\
\text { People who only owned } \\
\text { pets in } 2001 \text { did not differ } \\
\text { from non-owners in their } \\
\text { number of doctor visits. }\end{array}$ \\
\hline $\begin{array}{l}\text { Headey et al. } \\
(2007)\end{array}$ & $\begin{array}{l}\text { Chinese females } 25 \text { to } 40 \\
\text { years who did }(n=1,516) \\
\text { and did not own a dog } \\
(n=1,515)\end{array}$ & $\begin{array}{l}\text { Doctor visits, } \\
\text { physical } \\
\text { fitness, } \\
\text { physical } \\
\text { health, trouble } \\
\text { sleeping, sick } \\
\text { days }\end{array}$ & $\begin{array}{l}\text { Female dog owners had } \\
\text { more positive results than } \\
\text { non-owners on all } \\
\text { measures. }\end{array}$ \\
\hline
\end{tabular}


Table 2. cont'd.

Cross-Sectional Studies of the Relationship between Pet Ownership and Physical

Health

\begin{tabular}{|c|c|c|c|}
\hline Researchers & Sample & Measures & Results \\
\hline $\begin{array}{l}\text { Odendaal } \\
(2000)\end{array}$ & $\begin{array}{l}18 \text { dog owners in South } \\
\text { Africa }\end{array}$ & $\begin{array}{l}\text { Six neuro- } \\
\text { chemicals } \\
\text { known to } \\
\text { affect blood } \\
\text { pressure }\end{array}$ & $\begin{array}{l}\text { After interacting with their } \\
\text { dog, cortisol levels } \\
\text { decreased, while } \beta \text { - } \\
\text { endorphin, oxytocin, } \\
\text { prolactin, phenylacetic } \\
\text { acid, and dopamine levels } \\
\text { increased. }\end{array}$ \\
\hline \multirow[t]{2}{*}{$\begin{array}{l}\text { Rogers et al. } \\
\text { (1993) }\end{array}$} & $\begin{array}{l}\text { American seniors living in } \\
\text { mobile home parks who did } \\
(n=6) \text { and did not }(n=6) \\
\text { own a dog }\end{array}$ & $\begin{array}{l}\text { Health now } \\
\text { compared to } \\
5 \text { years ago }\end{array}$ & $\begin{array}{l}\text { Compared to senior non- } \\
\text { owners, senior dog owners } \\
\text { rated their health as better. }\end{array}$ \\
\hline & & $\begin{array}{l}\text { Number of } \\
\text { sick days in } \\
\text { past } 6 \text { months }\end{array}$ & $\begin{array}{l}\text { Compared to senior non- } \\
\text { owners, senior dog owners } \\
\text { had fewer sick days. }\end{array}$ \\
\hline
\end{tabular}

Psychological health. Researchers have found evidence that pet ownership, particularly dog ownership, is associated with psychological health benefits. In the sole longitudinal study of psychological outcomes, conducted by Serpell $(1990,1991)$ in the United Kingdom, dog owners' mental health (as measured by the General Health Questionnaire which assesses overall psychological well-being) improved 6 months after acquiring a dog and this improvement was maintained at 10 months. In contrast, people in the control group, who did not own a dog, did not experience significant changes in their overall psychological well-being throughout the 10-month study. Further, only 
people who accuired a dog exhibited a significant, albeit small, increase in their selfesteem levels from baseline to 10 months. These findings suggest that there may be a causal relation between dog ownership and psychological well-being.

The relationship between pet ownership and psychological well-being has been examined in at least nine cross-sectional studies. For example, Headey (1999) found that people who owned a dog or cat were less lonely than individuals who did not own a pet, an effect that was stronger for dog than cat owners. Similarly, in a sample of 339 Australians, Wood, Giles-Corti, Bulsara, and Bosch (2007) found that pet owners (of typically a dog or cat) were two times less likely to report frequently feeling lonely than individuals who did not own a pet.

Researchers have also documented the psychological benefits of pet ownership among the elderly and widows. In a study of 60 community-residing elders lower levels of depression and loneliness were documented among those who did, as opposed to did not, own a dog and/or cat (Roberts, McBride, Rosenvinge, Stevenage, \& Bradshaw, 1996). In another study of 298 seniors, male pet owners (of primarily a dog or cat) had higher self-esteem than males without a pet (Hecht, McMillin, \& Silverman, 2001). In contrast, senior women's self-esteem did not differ as a function of pet ownership, leading the researchers to suggest that other factors may interact with pet ownership to affect older women's self-esteem. Finally, in a study of 108 women who were recently widowed ( 2 months to 3 years ago), pet owners (typically of a dog) reported fewer psychogenic symptoms (e.g., fears and feelings of panic) and took fewer psychotropic medications than those who did not own a pet (Akiyama, Holtzman, \& Britz, 1986). 
The psychological benefits of pet ownership have also been noted in studies of women living alone. For example, among both female students and elderly women living alone, those living with a pet (usually a dog or cat) have been found to be less lonely than those without a pet (Goldmeier, 1986; Zasloff \& Kidd, 1994). Elderly women who lived alone with a pet also had higher surgency scores (i.e., were generally free from depression and desired to remain active), were more optimistic and less easily agitated than elderly women living alone without a pet (Goldmeier, 1986).

Other studies suggest that the psychological benefits of pet ownership may depend on marital status and gender. In a study of 302 pet-owning university faculty members, those who were unmarried and living without children were more likely than those who were married and/or living with children to report that they owned a pet (primarily a dog or cat) because they believed they would be lonely without the pet (Staats, Sears, \& Pierfelice, 2006). In addition, the findings of a study of 2,291 Americans suggested that the relationship between marital status and depression varies as a function of gender. Among those who were unmarried, female pet owners were less depressed than females who did not live with a dog or cat, whereas male pet owners were more depressed than their counterparts without a dog or cat (Tower \& Nokota, 2006). Among those who were married, female pet owners were slightly more depressed than females without a pet, while married men's depression did not vary as a function of pet ownership. Tower and Nokota concluded that unmarried women receive the greatest psychological benefits from pet ownership.

Taken together, these studies suggest that pets, particularly dogs, provide a 
number of psychological benefits, including better overall psychological well-being (Serpell, 1991), fewer psychological symptoms (Akiyama et al., 1986), increased levels of self-esteem (Hecht et al., 2001; Serpell, 1990), optimism and surgency (Goldmeier, 1986) and reduced levels of agitation (Goldmeier, 1986), depression (Roberts et al., 1996; Tower \& Nokota, 2006) and loneliness (Goldmeier, 1986; Headey, 1999; Roberts et al., 1996; Staats et al., 2006; Wood et al., 2007; Zasloff \& Kidd, 1994). Further, these benefits appear to apply to members of the general population and to particular subgroups, such as seniors, women, people living alone and people who are unmarried. These results also hold in different countries including the United Kingdom, the United States and Australia. A summary of these findings is provided in Table 3.

Table 3.

Studies of the Relationship between Pet Ownership and Psychological Health

\begin{tabular}{llll}
\hline Researchers & Sample & Measures & Results \\
\hline
\end{tabular}

\section{Longitudinal Studies}

Serpell $(1990,1991)$
47 people in the United Kingdom who acquired a dog and a control group of 26 non-owners were followed for 10 months
General Health Dog owners'

Questionnaire psychological well-being improved at 6 months and this effect persisted at 10 months. No significant changes for the control group.

Self-esteem Dog owners' self-esteem increased at 10 months. No significant changes for the control group. 
Table 3 cont ${ }^{9} d$.

Studies of the Relationship between Pet Ownership and Psychological Health

\begin{tabular}{llll}
\hline Researchers & Sample & Measures & Results \\
\hline
\end{tabular}

\section{Cross-Sectional Studies}

Akiyama et

al. (1986)

Goldmeier

(1986)

Headey

(1999)

Hecht et al. (2001)
Recently widowed women in the United States who did $(n=51)$ and did not $(n=57)$ own a pet

American seniors living alone $(n=56)$, alone with a pet $(n=60)$, with other people $(n=12)$ or with other people and a pet $(n=16)$

\section{1,011 Australians who did} or did not own a dog or cat

298 American seniors who did or did not own a pet
Health

symptoms

experienced

after death of

spouse

Medications

taken after

death of

spouse

Philadelphia

Geriatric

Center Morale

Scale

Loneliness

Self-esteem
Pet owners had fewer psychogenic symptoms than non-owners.

Pet owners took fewer psychotropic medications than non-owners.

No differences between pet owners and nonowners living with other people. Pet owners living alone were less lonely, had higher surgency scores, were more optimistic and less easily agitated than non-owners living alone.

Dog and cat owners were less lonely than nonowners.

Among men, pet owners had higher self-esteem than non-owners. No significant difference for women. 
Table 3 cont' $d$.

Studies of the Relationship between Pet Ownership and Psychological Health

\begin{tabular}{|c|c|c|c|}
\hline Researchers & Sample & Measures & Results \\
\hline \multirow[t]{2}{*}{$\begin{array}{l}\text { Roberts et al. } \\
(1996)\end{array}$} & $\begin{array}{l}60 \text { seniors in the United } \\
\text { Kingdom who did or did } \\
\text { not own a dog and/or cat }\end{array}$ & Loneliness & $\begin{array}{l}\text { Dog and/or cat owners } \\
\text { were less lonely than non- } \\
\text { owners. }\end{array}$ \\
\hline & & Depression & $\begin{array}{l}\text { Dog and/or cat owners } \\
\text { were less depressed than } \\
\text { non-owners. }\end{array}$ \\
\hline $\begin{array}{l}\text { Staats et al. } \\
(2006)\end{array}$ & $\begin{array}{l}\text { American university faculty } \\
\text { who did }(n=169) \text { and did } \\
\text { mot own a pet }(n=133)\end{array}$ & $\begin{array}{l}\text { Reason for pet } \\
\text { ownership }\end{array}$ & $\begin{array}{l}\text { Faculty with pets who } \\
\text { were unmarried and living } \\
\text { without children were } \\
\text { more likely than faculty } \\
\text { who were married and/or } \\
\text { living with children to } \\
\text { report keeping pets to } \\
\text { reduce their loneliness. }\end{array}$ \\
\hline $\begin{array}{l}\text { Tower and } \\
\text { Nokota } \\
(2006)\end{array}$ & $\begin{array}{l}\text { Americans living with } \\
(n=767) \text { and without } \\
(n=1,524) \text { a dog or cat }\end{array}$ & Depression & $\begin{array}{l}\text { Unmarried female dog or } \\
\text { cat owners less depressed } \\
\text { than female non-owners; } \\
\text { opposite true for } \\
\text { unmarried men. Married } \\
\text { female dog or cat owners } \\
\text { more depressed than } \\
\text { female non-owners; no } \\
\text { difference for men. }\end{array}$ \\
\hline
\end{tabular}


Dog Walking and Well-Being 16

Table 3 cont'd.

Studies of the Relationship between Pet Ownership and Psychological Health

\begin{tabular}{|c|c|c|c|}
\hline Researchers & Sample & Measures & Results \\
\hline $\begin{array}{l}\text { Wood et al. } \\
(2007)\end{array}$ & $\begin{array}{l}\text { Australians who did } \\
(n=200) \text { and did not } \\
(n=139) \text { own a pet }\end{array}$ & Loneliness & $\begin{array}{l}\text { Pet owners were } 2 \text { times } \\
\text { less likely than non- } \\
\text { owners to report } \\
\text { frequently feeling lonely. }\end{array}$ \\
\hline $\begin{array}{l}\text { Zasloff and } \\
\text { Kidd (1994) }\end{array}$ & $\begin{array}{l}\text { American female students } \\
\text { living alone }(n=34) \text {, alone } \\
\text { with a dog or cat }(n=24) \text {, } \\
\text { with other people }(n=55) \\
\text { or with other people and a } \\
\text { dog or cat }(n=35)\end{array}$ & Loneliness & $\begin{array}{l}\text { Females living alone } \\
\text { without a dog or cat were } \\
\text { lonelier than females } \\
\text { living alone with a dog or } \\
\text { cat and females living with } \\
\text { other people with or } \\
\text { without a dog or cat. }\end{array}$ \\
\hline
\end{tabular}

\section{The Relationship between Dog Walking and Well-Being}

Researchers have found that pets, primarily dogs and cats, provide a host of benefits, including social support (Bonas, McNicholas, \& Collis, 2000; McNicholas \& Collis, 2000), companionship (Dotson \& Hyatt, 2008; Holbrook, Stephens, Day, Holbrook, \& Strazar, 2001), the opportunity to nurture (Enders-Slegers, 2000; Holbrook et al., 2001), love and affection (Adéll-Båth, Krook, Sandqvist, \& Skantze, 1979; Siegel, 1990), security (Siegel, 1990; Quigley, Vogel, Robert, \& Anderson, 1983), entertainment (Holbrook et al., 2001; Salmon \& Salmon, 1983), and contact comfort (Charnetski, Riggers, \& Brennan, 2004; Johnson \& Meadows, 2002). Pets also act as stress buffers (Siegel, 1990; Raina et al., 1999; Allen, Blascovich, \& Mendes, 2002). However, dogs 
are unique in that, because of their need for exercise, they may increase their owners' physical activity. Given the health benefits of physical activity (Gilmour, 2007; U.S. Department of Health and Human Services, 1996), it is conceivable that dog walking is beneficial with respect to physical and psychological health.

Dog ownership, walking and total physical activity. Eight out of 10 studies, summarized in Table 4, found that dog owners walk more than people who do not own a dog. For example, in Serpell's (1991) longitudinal study people displayed a dramatic increase in the number/duration of their walks 1 month after acquiring a dog, an increase that persisted at 6 and 10 months. Indeed, dog owners' walking increased from approximately 1 hour a week at baseline to 5 hours a week at 10 months. Similarly, in Cutt, Knuiman, and Giles-Corti’s (2008d) 12-month longitudinal study comparing 92 Australians who became dog owners at some point during the study (new dog owners) with 681 Australians who did not own a dog throughout the study (continuous nonowners), at baseline new dog owners engaged in an average of 28 less minutes of walking than continuous non-owners, while at 12 months new dog owners walked, on average, 43 more minutes per week than continuous non-owners. Similar findings have been obtained in four cross-sectional studies of the amount of walking by members of the general population (e.g., Brown \& Rhodes, 2006; Cutt, Giles-Corti, Knuiman, Timperio, \& Bull, 2008b; Giles-Corti \& Donovan, 2003; Headey, 1999) and community-dwelling seniors (e.g., Dembicki \& Anderson, 1996; Rogers et al., 1993). However, two crosssectional studies of the general population did not find differences in the time spent walking by people who did versus did not own a dog (Bauman, Russell, Furber, \& 
Dobson, 2001; Schofield, Mummery, \& Steele, 2005).

Table 4.

Studies of Walking by People Who Do and Do Not Own a Dog

\begin{tabular}{llll}
\hline Researchers & Sample & Measure & Results \\
\hline
\end{tabular}

\section{Longitudinal Studies}

Cutt et al. $\quad 773$ Australians were (2008d) followed for 12 months after moving into new housing estates.

47 new dog owners in the United Kingdom were followed for 10 months
Minutes walking New dog owners $<$ Nonduring a usual owners at baseline week

New dog owners $>$ Nonowners at 12 months

Number/duration Increase in the of walks in the number/duration of past 2 weeks walks at 1 month and maintained at 6 and 10 months 
Table 4 cont'd.

Studies of Walking by People Who Do and Do Not Own a Dog

\begin{tabular}{|c|c|c|c|}
\hline Researchers & Sample & Measure & Results \\
\hline \multicolumn{4}{|c|}{ Cross-Sectional Studies } \\
\hline $\begin{array}{l}\text { Bauman et al. } \\
(2001)\end{array}$ & 894 Australians & $\begin{array}{l}\text { Hours walking } \\
\text { during previous } \\
\text { week }\end{array}$ & $\begin{array}{l}\text { Dog owners = Non- } \\
\text { owners }\end{array}$ \\
\hline $\begin{array}{l}\text { Brown \& } \\
\text { Rhodes } \\
(2006)\end{array}$ & 351 Canadians & $\begin{array}{l}\text { Minutes walking } \\
\text { during a usual } \\
\text { week }\end{array}$ & $\begin{array}{l}\text { Dog owners > Non- } \\
\text { owners }\end{array}$ \\
\hline $\begin{array}{l}\text { Cutt et al. } \\
(2008 \mathrm{~b})\end{array}$ & $\begin{array}{l}1,813 \text { Australians before } \\
\text { they moved into new } \\
\text { housing estates }\end{array}$ & $\begin{array}{l}\text { Minutes walking } \\
\text { during a usual } \\
\text { week }\end{array}$ & $\begin{array}{l}\text { Dog owners }>\text { Non- } \\
\text { owners }\end{array}$ \\
\hline $\begin{array}{l}\text { Dembicki \& } \\
\text { Anderson } \\
(1996)\end{array}$ & 127 American seniors & $\begin{array}{l}\text { Minutes walking } \\
\text { in a day }\end{array}$ & $\begin{array}{l}\text { Dog owners > Non- } \\
\text { owners }\end{array}$ \\
\hline $\begin{array}{l}\text { Giles-Corti \& } \\
\text { Donovan } \\
(2003)\end{array}$ & $\begin{array}{l}\text { 1,773 Australian } \\
\text { homemakers and workers }\end{array}$ & $\begin{array}{l}\text { Adjusted odds } \\
\text { ratio for } \\
\text { achieving } \\
\text { recommended } \\
\text { walking levels }\end{array}$ & $\begin{array}{l}\text { Dog owners were } 58 \% \\
\text { more likely to meet } \\
\text { guidelines than non- } \\
\text { owners }\end{array}$ \\
\hline $\begin{array}{l}\text { Headey } \\
(1999)\end{array}$ & 1,011 Australians & $\begin{array}{l}\text { Number of } \\
\text { walks per week }\end{array}$ & $\begin{array}{l}\text { Dog owners > Non- } \\
\text { owners }\end{array}$ \\
\hline $\begin{array}{l}\text { Rogers et al. } \\
(1993)\end{array}$ & $\begin{array}{l}12 \text { American seniors living } \\
\text { in mobile home parks }\end{array}$ & $\begin{array}{l}\text { Number of } \\
\text { walks per day }\end{array}$ & $\begin{array}{l}\text { Dog owners > Non- } \\
\text { owners }\end{array}$ \\
\hline $\begin{array}{l}\text { Schofield et } \\
\text { al. (2005) }\end{array}$ & 1,237 Australians & $\begin{array}{l}\text { Minutes walking } \\
\text { in past week }\end{array}$ & $\begin{array}{l}\text { Dog owners = Non- } \\
\text { owners }\end{array}$ \\
\hline
\end{tabular}

${ }^{a}$ Defined as achieving 12 or more sessions of walking amounting to at least 360 minutes in the past two weeks. 
Studies comparing the total amount of time people who do and do not own a dog engage in physical activities (including both walking and non-walking physical activities) have also yielded mixed findings, as shown in Table 5. In the sole longitudinal study, Cutt et al. (2008d) found that participants who did and did not acquire a dog during their 12 month study did not differ in the amount of time devoted to physical activity at both the outset and conclusion of the study. Cutt et al. suggested that variables confounded with dog acquisition (e.g., sociodemographic differences between the groups) may account for the lack of differences. Because both groups displayed very high levels of physical activity at baseline (i.e., new dog owners $M=278.37$ minutes; continuous nonowners $M=251.37$ minutes per week $)$, Cutt et al. also speculated that differences may not have occurred because new dog owners replaced some of their other physical activities with dog walking, as opposed to adding dog walking to their existing activities. On the other hand, in their cross-sectional study of 351 Canadians, Brown and Rhodes (2006) found that dog owners engaged in more total physical activity than people who did not own a dog. They also noted that dog walking was responsible for this difference. Two other cross-sectional studies have found significant differences in the physical activity levels of people who do and do not own a dog (Cutt et al., 2008b; Headey \& Zheng, 2007), while three cross-sectional studies have not (Dembicki \& Anderson, 1996; Schofield et al., 2005; Thorpe et al., 2006a). 
Table 5.

Studies of the Total Physical Activity of People Who Do and Do Not Own a Dog

\begin{tabular}{|c|c|c|c|}
\hline Researchers & Sample & Measure & Results \\
\hline
\end{tabular}

\section{Longitudinal Studies}

Cutt et al. $\quad 773$ Australians were (2008d) followed for 12 months after moving into new housing estates.

\section{Cross-Sectional Studies}

$\begin{array}{ll}\begin{array}{l}\text { Brown \& } \\ \text { Rhodes } \\ (2006)\end{array} & 351 \text { Camadians } \\ \begin{array}{l}\text { Cutt et al. } \\ (2008 b)\end{array} & \begin{array}{l}1,813 \text { Australians before } \\ \text { they moved into new } \\ \text { housing estates }\end{array}\end{array}$

Dembicki \& 127 American seniors Anderson (1996)

Headey \& 3,031 Chinese women Zheng (2007) 25 to 40 years
Number of New dog owners $=$ Nonminutes of owners at baseline and physical activity 12 months during a usual week

Minutes of physical activity Dog owners $>$ Nonowners during a usual week

Minutes of physical activity Dog owners $>$ Nonduring a usual week

Overall physical activity as Dog owners $=$ Nonassessed by the number and duration of physical activities

Frequency of Dog owners exercised exercising for at $36 \%$ more than nonleast 20 minutes owners in past week 
Table 5 cont'd.

Studies of the Total Physical Activity of People Who Do and Do Not Own a Dog

\begin{tabular}{lcll}
\hline Researchers & \multicolumn{1}{c}{ Sample } & Measure & \multicolumn{1}{c}{ Results } \\
\hline $\begin{array}{l}\text { Schofield et } \\
\text { al. (2005) }\end{array}$ & 1,237 Australians & $\begin{array}{l}\text { Minutes of } \\
\text { physical } \\
\text { activity in the } \\
\text { previous week }\end{array}$ & Dog owners = Non-owners \\
$\begin{array}{l}\text { Thorpe et al. } \\
\text { (2006a) }\end{array}$ & 2,533 American seniors & $\begin{array}{l}\text { Minutes of } \\
\text { physical } \\
\text { activity in the } \\
\text { previous week }\end{array}$ & Dog owners = Non-owners \\
& & & \\
\hline
\end{tabular}

One possible explanation for the failure of some studies to find differences in the walking and total physical activity of people who do and do not own a dog may stem from the simple reality that not all dog owners walk their dog. As shown in Table 6, researchers have found that $20 \%$ to $40 \%$, of dog owners do not walk their dog, with one study (Bauman et al., 2001) finding that as many as 59\% of dog owners do not walk their dog. Based on these figures, it may be that dog owners who do not walk their dog spend less time walking and engage in less total physical activity than both people who walk their dog and people who do not own a dog. 
Table 6.

Percentage of Dog Owners Who Do Not Walk Their Dog

\begin{tabular}{llc}
\hline \multicolumn{1}{c}{ Researchers } & \multicolumn{1}{c}{ Sample } & Do not walk their dog \\
\hline Bauman et al. (2001) & 410 Australian dog owners & $59 \%$ \\
Cutt et al. (2008a) & 629 Australian dog owners & $23 \%$ \\
Cutt et al. (2008b) & 804 Australian dog owners & $22 \%$ \\
Ham \& Epping (2006) & 1,282 American dog owners & $20 \%$ \\
Schofield et al. (2005) & 646 Australian dog owners & $40 \%$ \\
Slater et al. (1995) & 69 American dog owners & $33 \%$ \\
Suminski et al. (2005) & 215 American dog owners & $39 \%$ \\
\hline
\end{tabular}

${ }^{a}$ Dog walking was defined as walking the dog for a period of at least 10 minutes.

Studies comparing people who walk their dog, do not walk their dog or do not own a dog were examined in order to determine whether people who walk their dog engage in more walking and total physical activity than people who do not walk their dog or do not own a dog. As shown in Table 7, Cutt, Giles-Corti, and Knuiman (2008a) found that people who walked their dog spent more time walking and engaged in more physical activity per week than people who did not walk their dog. Another study found that people who did not walk their dog spent less time walking and engaged in less physical activity per week than people who did not own a dog (Bauman et al., 2001), while a third 
study found that people from households in which the dog was not walked were less physically active than people from households without a dog (Schofield et al., 2005). While studies have not specifically compared people who walk their dog versus people who do not own a dog, in Bauman et al.'s (2001) study dog owners who walked their dog for at least 1 hour a week spent more time walking and engaged in more physical activity than people who did not own a dog, while people who walked their dog for less than 1 hour a week spent less time walking and engaged in less physical activity than people who did not own a dog. Bauman et al.'s findings suggest that people who walk their dog for less than 1 hour a week (i.e., less than 10 minutes a day) do not receive sufficient exercise to achieve the health benefits associated with dog walking. 


\section{Table 7.}

Studies of Walking and Total Physical Activity by People Who Walk Their Dog, Do Not

Walk Their Dog or Do Not Own a Dog

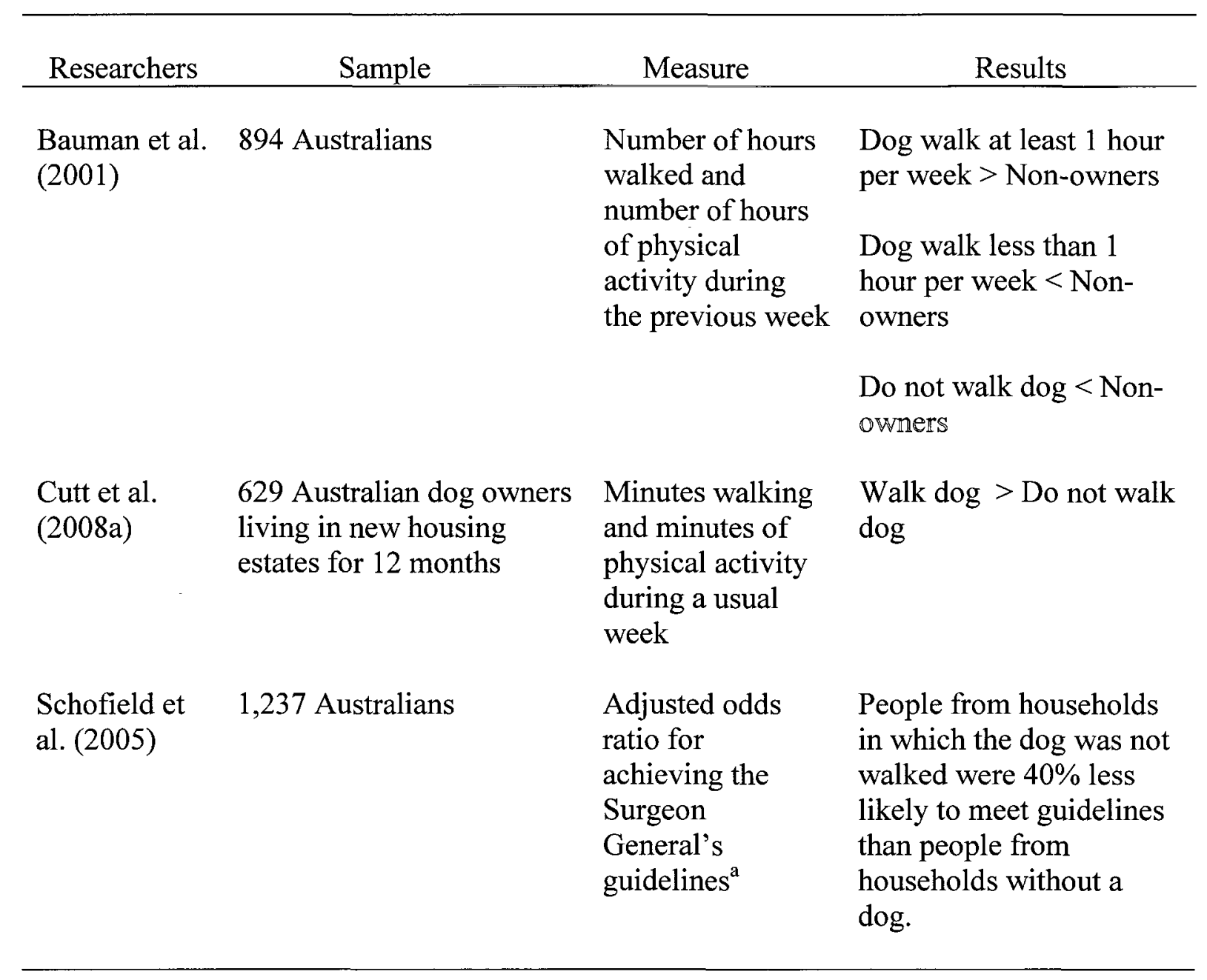

${ }^{a}$ In 1996, the United States Surgeon General recommended that adults receive at least 30 minutes of moderate physical activity on most, if not every day, of the week. This statement has been interpreted as recommending that individuals attain at least 150 minutes, 30 minutes on 5 days, of moderate physical activity a week. 
The preceding findings raise the possibility that people who walk their dog for more than minimal amounts of time may spend more time engaged in physical activity, in addition to dog walking, than people who do not walk their dog or do not own a dog. However, the work of Cutt et al. (2008a) suggests that this is not the case in that, when they subtracted time spent dog walking from dog walkers' total time devoted to physical activity, dog walkers only engaged in 11.8 more minutes of physical activity a week than people who did not walk their dog. Although researchers have not conducted a similar comparison of dog walkers and people who do not own a dog, it is likely the results would be similar.

Dog walking arsed well-being. Two longitudinal studies and one cross-sectional study have examined the relationship between dog walking and well-being. In Serpell's (1991) study, people displayed a marked increase in the number/duration of their walks 1 month after acquiring a dog, an increase that persisted at 6 and 10 months. Contrary to expectations, however, there was no relation between the increase in the number/duration of walks and dog owners' physical health at any time. This finding led Serpell to suggest that the physical health benefits associated with dog walking may take longer than 10 months to become apparent. While a positive relation was observed between the number/duration of walks and mental health at 6 months (Kendall $r=.34$ ), it was not maintained at 10 months. The small sample size and the fact that the dog-owning group decreased from 47 dog owners at baseline to 39 dog owners at 10 months may have reduced the power of Serpell's study. This suggests the need for research using a larger sample, as well as the need to examine the relationship between dog walking and 
physical and psychological health among dog owners who have owned their dog for longer periods of time.

In Thorpe et al.'s (2006b) 3-year study of 2,533 noninstitutionalized seniors, at baseline both senior dog owners who walked their dog at least three times a week and seniors without a dog who walked at least three times a week had mobility advantages, including higher usual and rapid walking speeds, than dog owners who walked their dog fewer than three times a week and people without a dog who walked fewer than three times a week. Three years later, all seniors experienced declines in their rapid and usual walking speeds, but only dog owners who walked their dog at least three times a week maintained their initial mobility advantage over dog owners who did not walk their dog at least three times a week and seniors who did not own a dog. However, Thorpe et al. note that their ability to make a causal inference about the effects of dog walking on health is limited because they failed to examine whether participants in any of the groups lost or acquired a dog over the 3-year period of their study.

Finally, Lacey (2004) used a cross-sectional design to compare the stress levels of women who did $(n=373)$ or did not $(n=117)$ own some type of pet. When these women were further divided into those who did or did not exercise (including walking and other types of exercise), there were no group differences in stress. These nonsignificant findings may have stemmed from the fact that the study was not limited to dog owners and/or the drastically unequal numbers of participants in the four groups (the largest group had 345 participants while the smallest had only 9). While among the 318 dog owners in Lacey's sample both the number of times the women walked their dog per 
week $(r=-.13)$ and the average length of their walks $(r=-.10)$ were associated with lower stress levels, given the low magnitude of these correlations, limited emphasis should be placed on these findings.

The limitations of existing research suggest the need for more rigorous research examining the dog walking-health benefits relation. This research should include a sufficiently large sample of people who have owned their dog for varying lengths of time. Given the substantial percentage of dog owners who do not walk their dog, researchers should also compare the well-being of dog owners who do and do not walk their dog. Similarly, researchers need to consider whether dog owners spend sufficient time walking their dog to realize the health benefits that may result from dog waiking. According to both Canada's Physical Activity Guide to Healthy Active Living (Health Canada and the Canadian Society for Exercise Physiology, 1998) and the updated recommendations from the American College of Sports Medicine and the American Heart Association (Haskell et al., 2007), a minimum of 10 minutes of physical activity at each session is required to obtain health benefits. Based on figures from various studies, it appears that a sizeable number of dog owners do not walk their dog long enough to receive health benefits. For example, $9 \%$ of the dog walkers in Slater, Robinson, Zoran, Wallace, and Scarlett's (1995) sample of 69 American dog owners reported that their dog walks lasted for less than 10 minutes. Similarly, Ham and Epping (2006) found that $19.8 \%$ of 1,282 American dog owners did not walk their dog for at least 10 minutes a day.

\section{The Present Study}

While the three studies that examined the relationship between dog walking and 
well-being (Lacey, 2004; Serpell, 1991; Thorpe et al., 2006b) provided only limited evidence that dog walking is beneficial for human health, as noted earlier, these studies suffered from a number of limitations (e.g., people had owned a dog for at most 10 months). More importantly, these studies did not examine whether health varied as a function of whether individuals walked their dog, walked their dog minimally (i.e., for sessions lasting less than 10 minutes) or not at all, or did not own a dog.

In view of the above, the present study is designed to assess a) whether people who walk their dog engage in more physical activity (both total walking for leisure and total physical activity) and, as a result, have better physical and psychological health than both people who walk their dog minimally (i.e., for periods of less than 10 minutes per session) or not at all and people without a dog, and b) whether people who walk their dog minimally or not at all engage in less physical activity (both total walking for leisure and total physical activity), and hence have poorer physical and psychological health than people who do not own a dog. Finally, if results reveal that dog owners who walk their dog engage in more total physical activity than both dog owners who walk their dog minimally or not all and people who do not own a dog, the present study will examine if, when time spent dog walking is excluded, there are no longer significant differences in the total physical activity levels of dog owners who walk their dog compared to both dog owners who walk their dog minimally or not at all and people who do not own a dog.

Using a correlational approach, this study also examines the linear relations between the amount of time spent dog walking for periods lasting at least 10 minutes and dog owners' physical and psychological health. To increase power, these relations are 
assessed while controlling for the impact of other factors known to affect health, such as stress levels. 


\section{Method}

\section{Participants}

Individuals at least 18 years of age completed a 20 minute survey to "explore the relationship between physical activity and well-being among people who do and do not own a dog." Participants were recruited using several methods. First, snowball sampling was conducted by sending an e-mail with a description of the study and the link to the survey to family and friends asking them to complete the survey on-line and/or forward the e-mail to other people they thought would be willing to complete it. Second, participants were directed to the on-line survey using posters placed in various locations in the community (e.g., libraries, community centers and laundromats). Third, ads seeking survey participants were placed in community newspapers in Ottawa and on Facebook sites across Canada. Fourth, the link to the survey was placed on a variety of Internet websites and forums, with an emphasis on pet-related sites (e.g., dog kennels and a pet discovery center). Fifth, in order to obtain a cross-section of people, a sheet containing a description of the survey and the link to the survey was distributed in-person at various community locations (e.g., dog walking parks and pet stores). Sixth, copies of a description of the survey were made available at various locations (e.g., pet stores, veterinarian offices, animal hospitals and customer service booths at large shopping centers). Given that in 2005 , only $61 \%$ of Canadian households had Internet (Statistics Canada, 2006a), a paper version of the questionnaire was available to participants who did not have Internet access or who preferred to complete a paper version of the survey. 
The sample was comprised of $658^{1}$ ( 523 females, 134 males, 1 missing)

Canadians who ranged in age from 18 to 77 years $(M=37.89, S D=12.98$ years). Most commonly, participants were married $(41.6 \%, n=273)$ or common law/cohabiting ${ }^{2}$ $(19.6 \%, n=129)$, although almost a third were single $(29.1 \%, n=191)$. Relatively few participants indicated that they were divorced $(5.3 \%, n=35)$, separated $(3.5 \%, n=23)$, and widowed $(0.9 \%, n=6)$. Participants' education ranged from at most some high school $(4.0 \%, n=26)$, finished high school $(10.5 \%, n=69)$, some college or university $(28.7 \%, n=188)$, a college degree $(16.0 \%, n=105)$, a university degree $(21.8 \%, n=$ $143)$, to two or more university degrees $(19.1 \%, n=125)$. In addition, only $100(14.8 \%)$ of the participants were full-time students. Equal numbers of participants came from the various income levels, including less than $\$ 20,000(20.3 \%, n=129), \$ 20,000$ to $\$ 34,999$ $(16.7 \%, n=106), \$ 35,000$ to $\$ 49,999(17.8 \%, n=113), \$ 50,000$ to $\$ 64,999(16.5 \%, n=$ $105)$, and $\$ 80,000$ or above $(20.0 \%, n=127)$, with one exception: only $8.7 \%(n=55)$ of the participants earned between $\$ 65,000$ and $\$ 79,999$ before taxes. In addition, most

\footnotetext{
${ }^{1}$ Power analyses were conducted separately for the analyses of covariance (ANCOVAs) and regression analyses. For an a priori alpha of .05, and assuming a medium effect size of .25, the ANCOVAs required at least 207 participants (i.e., 69 participants per cell) to achieve a power of .90 (selected given that it was expected that cell sizes would be unequal) (Cohen, 1988). The hierarchical regression analyses, with 21 proposed predictors (including demographic variables, additional variables known to affect human health and the predictor variable, all described later) and an a priori alpha of .05, and assuming a medium effect size of .15, required a minimum of 195 participants for a power of .90 (Cohen, 1988). Given these estimates, data was collected from at least 195 participants.

${ }^{2}$ In Canada, persons who have lived in a conjugal relationship for at least 12 continuous months are considered to be in a common-law relationship for legal purposes, such as income tax. Prior to one year, individuals are considered to be cohabitating.
} 
participants indicated that they lived with other people $(82.5 \%, n=539)$. On the whole, then, the participants were typically well-educated young or middle-aged adults, primarily women, who earned reasonable incomes and were married or living with other people.

\section{Measures}

The questionnaire package, which appears in Appendix A, included measures of participants' demographic characteristics, dog ownership, dog walking, physical activity, physical and psychological health and additional variables known to influence level of exercise and physical and psychological health. To avoid order effects, paper versions of the questionnaire presented the various measures in random order, except the questions for dog owners, which were always placed at the end of the questionnaire in order to avoid confusion.

Demographic measures. Participants were asked about their sex, age, marital status, level of education, income before tax and whether they lived with other people. These variables were included in order to statistically control their potential impact on participants' physical activity and physical and psychological health. Participants were also asked where they currently lived in order to restrict the sample to residents of Canada and, as a result, 17 participants from a variety of countries (e.g., Denmark, Mexico, the Philippines, the United Kingdom and the United States) were excluded.

\section{Predictor Variables}

Measures of dog ownership and dog walking. This section of the survey consisted of questions designed to determine whether participants were dog owners and, 
if so, how much time they spent dog walking. Participants were first asked to indicate whether they owned a dog or cat. Because researchers have found a positive relationship between cat ownership and human health (Headey \& Grabka, 2007; Wood et al., 2007), 436 cat owners were excluded from the study. Because of the possible ongoing benefits of earlier dog ownership, 3 respondents who owned a dog within the past 6 months, but not at the time of the study, were also excluded.

Dog owners were asked whether they walk their dog and, if so, whether their dog walks typically last for less than 10 minutes or 10 or more minutes. Because at least 10 minutes of physical activity is required to obtain health benefits (Haskell et al., 2007; Health Canada and the Canadian Society for Exercise Physiology, 1998), dog owners who indicated that they typically walk their dog for less than 10 minutes per walk were classified as dog owners who walk their dog minimally (i.e., for sessions lasting less than 10 minutes) or not at all.

To determine the number of minutes a week dog owners spend walking their dog, dog owners were asked to indicate approximately how long they spent walking their dog on each of the last 7 days. Dog owners were also asked if they jog with their dog and, if so, how much time they spent jogging with their dog in the last week, excluding any periods lasting less than 10 minutes. The number of minutes dog owners spent jogging and walking with their dog was then summed to create a measure of 'minutes spent dog walking.'

\section{Physical Activity Criterion Variables}

Physical activity. Participants were asked a series of questions about the physical 
activities they engaged in during the past week. First, participants were asked to indicate how much time they spent walking for transportation (e.g., walking to work or to a store), excluding both walks that lasted less than 10 minutes and time spent walking for transportation with their dog. Second, participants were asked how much time they spent engaged in physical activities for transportation other than walking (e.g., bicycling or jogging to get to work or to a store), excluding any physical activity for transportation that lasted for less than 10 minutes and that was done with their dog. Third, participants were asked to indicate the amount of time they spent walking for leisure, excluding walks that lasted less than 10 minutes, walking for transportation and dog walking. Fourth, participants were asked to list all of the non-walking, non-transportation related physical activities, other than jogging with their dog, that they engaged in during their leisure time for at least 10 minutes a session and to indicate the total amount of time they spent on each activity in the past week.

Using the above information three measures of physical activity were created: first, the criterion variable, total walking during leisure time, was calculated by summing the number of minutes walking for leisure and the variable minutes dog walking and second, the criterion variable, total physical activity time, was derived from the sum of total walking time during leisure (including dog walking), time walking for transportation, time spent on non-walking physical activities for transportation, and time spent engaged in non-walking physical activities during leisure time. Third, the criterion variable, total non-dog walking physical activity, was calculated by subtracting time dog walking from total physical activity time. 


\section{Health $\mathbb{C}$ rititerion Viriables}

Measures of physical health. Participants were asked to indicate their height and weight in order to calculate their Body Mass Index (BMI) using the following formula: BMI $=$ weight $(\mathrm{kg}) /$ height $(\mathrm{m})^{2}$ (Health Canada, 2003). Participants were also asked how many times they visited any type of medical doctor in the past year, how many prescription medications they took in the past month (excluding birth control pills), and how they rated their current health on a scale ranging from 1 (poor) to 5 (excellent).

Measures of psychological health. Psychological health was assessed using measures of depression, positive and negative mood, and trait anxiety.

Using scales ranging from 0 (rarely or none of the time [less than I day a week]) to 3 (most or all of the time [5-7 days a week]) participants completed Radloff's (1977) 20-item Center for Epidemiologic Studies Depression Scale (CES-D) which assesses how frequently they have experienced symptoms of depression during the past week (e.g., "I felt sad," "I thought that my life had been a failure"). The CES-D scale is internally consistent $(\alpha=.85)$ and has modest test-retest correlations after 2 weeks to 12 months (except in one case, all test-retest $r \mathrm{~s}=.45$ to .70 ). The scale also demonstrates concurrent validity as it is highly correlated with the Beck Depression Inventory $(r=.86$, Santor, Zuroff, Ramsay, Cervantes, \& Palacios, 1995) and other measures of depression, such as the Lubin Depression Adjective Checklist and the Bradburn Negative Affect scale $(r s=.51$ to .63 , Radloff, 1977).

Using scales ranging from 1 (very slightly or not at all) to 5 (extremely), participants indicated how often, in general, they experienced each of the 20 mood states 
in Watson, Clark, and Tellegen's (1988) Positive and Negative Affect Schedule (PANAS). The 20 items form two 10-item scales: the positive affect scale includes items such as interested, strong, enthusiastic and proud and the negative affect scale includes items such as hostile, scared, guilty and ashamed. Both positive $(\alpha=.88)$ and negative ( $\alpha=.87)$ affect scales of the PANAS are internally consistent and, over a period of eight weeks, have test-retest reliabilities of .68 and .71 for the positive and negative affect scales, respectively. When correlated with two corresponding mood factors derived from a lengthier mood scale, the PANAS scales demonstrated excellent convergent ( $r s=.93$ to .94$)$ and discriminant $(r s=-.08$ to -.12$)$ validity.

Although Spielberger, Gorsuch, Lushene, Vagg, and Jacobs' (1983) State-Trait Anxiety Inventory assesses both state and trait anxiety, only trait anxiety levels were assessed in the present study. Participants responded to the 20 -items in the trait anxiety scale (e.g., "I lack self-confidence," "I feel like a failure") using 4-point scales ranging from 1 (almost never) to 4 (almost always). The trait anxiety scale has excellent internal consistency ( $\alpha \mathrm{s}=.89$ to .91 ) among working adults, college students and military recruits. Among college students the 1-hour, 20-day and 104-day test-retest reliability correlations ranged between .73 and .86. According to Spielberger et al. (1983), the trait anxiety scale has construct validity because it can discriminate subjects in the general population from psychiatric inpatients, who often experience anxiety as a major symptom (Spielberger et al., 1983). Evidence of the concurrent validity of the trait-anxiety scale is provided by its strong correlation with other measures of trait anxiety, such as the IPAT Anxiety Scale and the Taylor Manifest Anxiety Scale $(r s=.75$ to .80$)$. 


\section{Additionimal Measunes of Health}

Because they can affect well-being, participants were asked questions in order to determine how many years they have owned a dog, their attachment to their dog, their stress levels and whether they experienced a traumatic event in the past month. In addition, they answered questions to assess the health-promoting factors associated with dog ownership. Finally, participants were asked about the amount of time they spent in nature and the amount of time they spent in physical activity other than dog walking.

Years of dog ownership. The number of years of dog ownership was included as a control variable in view of Serpell's (1991) suggestion that the health benefits of dog walking become apparent only after a substantial length of time. Consistent with this,

Cavanaugh, Leonard, and Scammon (2008) found a positive relation between number of years owning a dog and life satisfaction.

Attachment. Pet attachment was assessed using Stallones, Marx, Garrity, and Johnson's (1990) 8-item Pet Attachment Questionnaire (PAQ), which includes items that are assessed using various response formats. Examples of items include "To what extent do you agree with the statement: No family is complete until there is a pet in the home" and "Would you say that owning a pet has helped your health?" Stallones et al. (1990) reported that all 8 items loaded strongly on one pet attachment factor. In addition, the scale is internally consistent $(\alpha=.75)$ and evidence for its face validity is provided by the fact that, as expected, never married individuals and individuals who had sole responsibility for their pet had the highest attachment levels (Stallones et al., 1990).

Stress. In Cohen, Kamarck, and Mermelstein's (1983) Perceived Stress Scale 
(PSS), participants used scales ranging from 0 (never) to 4 (very often) to rate how often, in the past month, their lives were unpredictable, uncontrollable and overloaded as assessed by 14 items (e.g., "felt that you were unable to control the important things in your life?," "felt difficulties were piling up so high that you could not overcome them?"). When Cohen et al. (1983) tested the PSS with college freshmen living in residence, college students in an introductory personality course and individuals attending a community smoking cessation program, the scale was internally consistent $(\alpha \mathrm{s}=.84, .85$ and .86 for the three groups, respectively). In addition, the 2-day test-retest reliability of the scale for college students living in residence was .85. The PSS has concurrent validity in that the PSS scores of college students living in residence and in an introductory personality course were positively correlated with their ratings of the impact of stressful life events on a modified version of the College Student Life-Event Scale ( $r s$ $=.24$ to .35 ; Cohen et al., 1983). It also has predictive validity in that the PSS scores of college freshmen living in residence were positively correlated at .20 with their use of health centres over a 5-week period (Cohen et al., 1983).

Traumatic experiences. Because experiencing a traumatic event may adversely affect participants' well-being, at the end of the PSS scale they were asked whether, in the past month, they had experienced a traumatic event such as the death of a family member.

Benefits of dog ownership. To isolate the extent to which it is dog walking that affects dog owners' health, as opposed to the health-promoting factors associated with pets more generally, questions were created to measure the extent to which dogs provided 
their owners with social support, companionship, the opportunity to nurture, love and affection, security, entertainment, contact comfort, and act as a stress buffer. The social support scale consisted of 3 items (e.g., "When things go wrong, my dog is there for me"), the companionship scale 3 items (e.g., "My dog is a source of companionship"), the opportunity to nurture scale 3 items (e.g., "My dog gives me something to care for"), the love and affection scale 2 items (e.g., "My dog gives me affection"), the security scale 2 items (e.g., "My dog makes me feel safe"), the entertainment dog scale 2 items (e.g., "My dog makes me laugh"), the contact comfort from dog scale 2 items (e.g., "Hugging my dog makes me feel good"), and the stress buffer scale 2 items (e.g., "When I am stressed, my dog is a source of comfort to me"). The items in each of the scales ranged from 1 (strongly agree) to 5 (strongly disagree). ${ }^{3}$

Time spent in nature. In order to control for the beneficial effects of spending time in natural environments on human health (Godbey, Graefe, \& James, 1992; Hull \& Michael, 1995), participants were asked to indicate how much time they spent in a natural environment (e.g., park, forest, countryside) during the past week, excluding any time spent dog walking.

Time spent on non-dog walking physical activity. Researchers have found that, as the amount of time people engage in physical activity increases, health benefits increase (Haskell et al., 2007; U.S. Department of Health and Human Services, 1996). To control for the amount of non-dog walking physical activity that participants engaged

${ }^{3}$ The scales assessing the health-promoting benefits of pets were recoded so that higher scores indicated that dog owners received fewer benefits from their dog. 
in over the course of a week, the variable time spent on non-dog walking physical activity was created by subtracting minutes dog walking from participants' total physical activity scores.

\section{Additional Measure for Exercise and Health Hypotheses}

The 13-item short form Marlowe-Crowne Social Desirability Scale was included in the questionnaire to assess the extent to which participants provided socially desirable responses (M-C SDS; Reynolds, 1982). Participants responded either True or False to each item (e.g., "I am always courteous, even to people who are disagreeable," "I'm always willing to admit it when I make a mistake"). According to Reynolds (1982), the M-C SDS is internally consistent, $r=.76$, and its concurrent validity is reflected by its high correlation with the original 33-item Marlowe-Crowne Scale, $r=.93$. 


\section{Results}

Preliminary analyses were conducted to examine the internal consistency of the scales, assess the descriptive statistics of the various measures, and examine the intercorrelations among the predictor and criterion variables. The main analyses then examined differences in the physical activity (total time walking for leisure and total physical activity) and health (physical and psychological) of dog owners who walk their dog, dog owners who walk their dog minimally or not all, and people who do not own a dog, after controlling for any significant covariates. These analyses also examined the linear relation between the amount of time dog walking and the physical and psychological health of dog owners who walk their dog. Finally, additional analyses were conducted to identify any confounded variables that might provide alternative explanations for the observed significant relations.

\section{Preliminary Analyses}

Internal consistency and descriptive statistics of the health measures. As shown in Table 8, the four measures of physical health were moderately intercorrelated, with one exception: participants' BMI scores were independent of the number of visits they made to a doctor in the previous year. Nevertheless, the average of these inter-item correlations was .26 and together they were associated with $\alpha=.59$. Given this, a composite measure of physical health was formed by calculating the mean of the standardized scores of the four physical health measures. ${ }^{4}$ Looking at the descriptive

\footnotetext{
${ }^{4}$ Although an item analysis indicated that excluding BMI scores increased the value of alpha to .67 , the results of the subsequent analyses did not differ as a function of whether
} 
statistics in Table \& indicated that, as a group, these participants were categorized as overweight (Health Canada, 2003), saw a physician about 4 or 5 times in the past year, took between 1 and 3 prescribed medications in the past month and regarded their physical health as very good.

Table 8.

Correlations and Descriptive Statistics for the Measures of Physical Health (Untransformed)

\begin{tabular}{lcccccc}
\hline \multicolumn{1}{c}{ Variable } & 2 & 3 & 4 & $M$ & $M d n$ & $S D$ \\
\hline 1. BMI & .03 & $.17^{* *}$ & $.22^{* *}$ & 26.32 & 25.00 & 6.32 \\
2. Doctor visits & - & $.52^{* *}$ & $.31^{* *}$ & 4.55 & 3.00 & 6.56 \\
3. Medications & & - & $.39^{* *}$ & 1.25 & 1.00 & 1.79 \\
4. Health rating & & & - & 1.59 & 2.00 & 0.95 \\
\hline
\end{tabular}

${ }^{\mathrm{a}}$ Health ratings were reverse coded resulting in higher scores reflecting poorer health. ${ }^{* *} p<.01$, two-tailed.

As shown in Table 9, item analyses revealed that the four individual measures of psychological health were internally consistent, with $\alpha$ s ranging from .89 for the positive affect scale to .94 for the trait anxiety scale. Given this, total scale scores were formed by

or not BMI scores were included in the composite measure of participants' physical health. 
calculating the mean, resulting in higher scores reflecting more depression, negative affect, trait anxiety and, after reverse coding, less positive affect. Examining the descriptive statistics shown in Table 9 revealed that this sample of participants, on the whole, was rarely depressed, experienced moderate levels of positive affect, low levels of negative affect, and had reasonably low levels of trait anxiety. Because the four measures of psychological health were significantly inter-correlated $(r \mathrm{~s}=.46$ to $.81, p \mathrm{~s}<$ $.01, M r=.69, \alpha=.89$ ), a composite measure of psychological health was formed by calculating the mean of participants' standardized scores on the four measures of psychological health. ${ }^{5}$

Table 9.

Results of Item Analyses and Descriptive Statistics for the Measures of Psychological Health (Untransformed)

\begin{tabular}{lccccccc}
\hline \multicolumn{1}{c}{ Scale } & $\begin{array}{c}N \text { of } \\
\text { items }\end{array}$ & $\begin{array}{c}M \text { inter- } \\
\text { item } r\end{array}$ & $\alpha$ & $\begin{array}{c}\text { Possible } \\
\text { range }\end{array}$ & $M$ & $M d n$ & $S D$ \\
\hline Depression & 20 & .33 & .91 & $0-3$ & 0.57 & 0.45 & 0.47 \\
Positive affect & 10 & .46 & .89 & $1-5$ & 2.81 & 2.70 & 0.75 \\
Negative affect & 10 & .43 & .88 & $1-5$ & 1.63 & 1.40 & 0.62 \\
Trait anxiety & 20 & .43 & .94 & $1-4$ & 1.93 & 1.75 & 0.58 \\
\hline
\end{tabular}

${ }^{5}$ When the measure with the lowest correlation with the other measures, positive affect $(r \mathrm{~s}=.46$ to $.66, p \mathrm{~s}<.01)$, was excluded from the composite measure of psychological health, Cronbach's alpha increased to .91 . However, because the results of the subsequent analyses did not vary as a function of whether or not positive affect was included, the positive affect scale was retained in the composite measure of psychological health. 
Descriptive statistics of activity measures. As shown in Table 10, dog owners who walked their dog, on average walked it for 6.4 hours (381.49 minutes per week). On average participants spent approximately 6.1 hours walking for leisure (367.02 minutes per week) and 6.6 hours engaged in non-walking physical activity (395.56 minutes per week). Finally, on average, participants spent 11.7 hours (701.49 minutes per week) engaged in all types of physical activity.

Table 10.

Descriptive Statistics and Correlations between the Predictor and Criterion Activity Measures (Untransformed)

\begin{tabular}{lccccccc}
\hline \multicolumn{1}{c}{ Variable } & $M$ & $M d n$ & $S D$ & 2 & 3 & 4 \\
\hline $\begin{array}{l}\text { Predictor variable: } \\
\text { 1. Time dog walking }\end{array}$ & 381.49 & 325.00 & 269.69 & $.88^{* *}$ & $.17^{* *}$ & $.54^{* *}$ \\
Criterion variables: & & & & & & \\
2. Time walking for leisure & 367.02 & 297.50 & 325.47 & - & $.37^{* *}$ & $.70^{* *}$ \\
3. Non-dog walking physical activity & 395.56 & 300.00 & 421.19 & & - & $.85^{* *}$ \\
4. Total physical activity & 701.49 & 550.00 & 595.60 & & & & - \\
\hline
\end{tabular}

${ }^{* *} p<.01$, two-tailed.

Internal consistency and descriptive statistics of potential covariates. As displayed in Table 11, item analyses revealed that the scales measuring potential 
covariates had acceptable internal consistency, with as ramging from .66 for the companionship scale to .89 for the Perceived Stress Scale. However, only four of the eight scales designed to measure the health-promoting benefits of dog ownership were internally consistent: social support, companionship, opportunity to nurture and stress buffer. The four heterogeneous scales (i.e., the measures of love and affection, security, entertainment and contact comfort) were therefore dropped from the analyses. The companionship scale was also dropped because of its restricted variance (i.e., the average response for $95.6 \%$ of participants was either agree or strongly agree).

As may be seen from the descriptive statistics in Table 11, pet owners had moderately high levels of attachment to their dog and participants, as a whole, had relatively low levels of stress and moderately high levels of social desirability. Among dog owners, in terms of the benefits of pet ownership, dog owners felt strongly that their dog provided social support, the opportunity to nurture and acted as a stress buffer, while they felt very strongly that their dog was a source of companionship. 
Table 11.

Results of Item Analyses and Descriptive Statistics for Potential Covariates

\begin{tabular}{|c|c|c|c|c|c|c|c|}
\hline Scale & $N$ of & $M$ inter- & $\alpha$ & $\begin{array}{c}\text { Possible } \\
\text { Rano }\end{array}$ & $M$ & $M d n$ & $S D$ \\
\hline stale & & & $\alpha$ & & $M$ & Man & $S D$ \\
\hline Pet attachment ${ }^{\mathrm{a}}$ & 7 & .28 & .72 & $0-19$ & 13.12 & 13.00 & 3.09 \\
\hline Perceived Stress Scale & 14 & .37 & .89 & $0-4$ & 1.57 & 1.50 & 0.65 \\
\hline Social desirability & 13 & .14 & .68 & $0-1$ & 0.58 & 0.62 & 0.22 \\
\hline \multicolumn{8}{|l|}{ Benefits of pets: } \\
\hline Social support & 3 & .57 & .79 & $1-5$ & 4.19 & 4.33 & 0.81 \\
\hline Companionship $^{\mathrm{a}}$ & 2 & .49 & .66 & $1-5$ & 4.68 & 5.00 & 0.55 \\
\hline Nurture $\operatorname{dog}^{\mathrm{a}}$ & 2 & .52 & .67 & $1-5$ & 4.22 & 4.50 & 0.77 \\
\hline Stress buffer & 2 & .51 & .67 & $1-5$ & 4.19 & 4.50 & 0.78 \\
\hline
\end{tabular}

${ }^{a}$ After deleting one item with a low item-total correlation.

\section{Main Analyses}

After ensuring that the assumptions underlying the analysis of correlations, ANCOVA and hierarchical regression analysis (Tabachnik \& Fidell, 2007) were satisfied, the simple correlations between the predictor and criterion variables were examined and planned comparisons and hierarchical regression analyses controlling for significant covariates were conducted to test the hypotheses. Note that to meet the assumption of normality, and in some cases to reduce the number of outliers, 
transformations were performed on all of the criterion variables, namely total walking for leisure, total physical activity, physical activity other than dog walking, physical health and psychological health. In addition, the predictor variable 'number of minutes dog walking' was transformed and subsequently centered. It should also be noted that the following potential covariates were also transformed: age, the Perceived Stress Scale, the social support from the dog scale, the nurture dog scale, the stress buffer scale, years of dog ownership, time in nature and time spent on non-dog walking physical activity. ${ }^{6}$

Participants were assigned to one of three groups depending on whether they walked their $\operatorname{dog}(n=499)$, walked their dog minimally or not at all $(n=71)$, or did not owm a dog $(n=88)$. Nonorthogonal planned comparisons were then conducted to examine the effects of group membership on participants' physical activity and health scores.

Hypotheses regarding physical activity. Three nonorthogonal planned comparisons were conducted to examine the effects of group membership on participants' total time spent walking for leisure and total time engaged in physical activity, using a Bonferonni corrected alpha of .017 for each criterion variable. It should be noted that, because single adults are more likely to be active than other groups (Cameron, Craig, \& Paolin, 2005), marital status was dichotomized as single versus all others.

It was hypothesized that dog owners who walked their dog would engage in more

\footnotetext{
${ }^{6}$ All the measures were normalized using square root transformations with the exception of age, which was log transformed.
} 
total time walking for leisure over the course of a week than dog owners who walked their dog minimally or not at all. Consistent with this, and after controlling for the effects of age, $\beta=.09, t(604)=2.58, p<.05$, income, $\beta=.02, t(604)=.47$, ns, and social desirability, $\beta=.03, t(604)=.90, \mathrm{~ns}$, dog owners who walked their $\operatorname{dog}(M=20.01 \mathrm{sqrt}$ mins., $S E=0.34$ sqrt mins.) engaged in significantly more total time walking for leisure than dog owners who walked their dog minimally or not at all $(M=5.09$ sqrt mins., $S E=$ 0.89 sqrt mins.), $F(1,604)=246.20, p<.001, \eta^{2}=.290$. It was also hypothesized that dog owners who walked their dog would engage in more total time walking for leisure over the course of a week than those who did not own a dog. As hypothesized, and after controlling for social desirability, $\beta=.05, t(637)=1.61$, ns, dog owners who walked their $\operatorname{dog}(M=20.13$ sqrt mins., $S E=0.33$ sqrt mins. $)$ engaged in significantly more total time walking for leisure than people who did not own a $\operatorname{dog}(M=6.66$ sqrt mins., $S E=0.77$ sqrt mins.), $F(1,637)=258.87, p<.001, \eta^{2}=.289$.

Finally, it was hypothesized that people who did not own a dog would spend more time walking for leisure than those who walked their dog minimally or not at all. Contrary to expectations, and after controlling for the effects of age, $\beta=.09, t(604)=$ $2.58, p<.05$, income, $\beta=.02, t(604)=.47, \mathrm{~ns}$, and social desirability, $\beta=.03, t(604)=$ $.90, \mathrm{~ns}$, people who did not own a $\operatorname{dog}(M=6.95$ sqrt mins., $S E=0.80$ sqrt mins. $)$ and dog owners who walked their $\operatorname{dog}$ minimally or not at all $(M=5.09$ sqrt mins., $S E=0.89$ sqrt mins.) did not differ in the total amount of time they spent walking for leisure, $F(1$, $604)=2.40, \mathrm{~ns}, \eta^{2}=.004$.

With respect to total physical activity it was hypothesized that dog owners who 
walked their dog would engage in more total physical activity over the course of a week than dog owners who walked their dog minimally or not at all. As hypothesized, and after controlling for the effects of sex, $\beta=-.09, t(636)=-2.66, p<.01$, marital status, $\beta=$ $-.12, t(636)=-3.50, p<.01$, and social desirability, $\beta=.10, t(636)=2.84, p<.01, \mathrm{dog}$ owners who walked their $\operatorname{dog}(M=26.87$ sqrt mins., $S E=0.41$ sqrt mins. $)$ engaged in significantly more total physical activity than dog owners who walked their dog minimally or not at all $(M=13.46$ sqrt mins., $S E=1.08$ sqrt mins. $), F(1,636)=134.38, p$ $<.001, \eta^{2}=.174$

It was also hypothesized that dog owners who walked their dog would engage in more total physical activity over the course of a week than those who did not own a dog. As hypothesized, and after controlling for the effects of social desirability, $\beta=.10, t(640)$ $=2.73, p<.01$, dog owners who walked their $\operatorname{dog}(M=26.60$ sqrt mins., $S E=0.42$ sqrt mins.), engaged in significantly more total physical activity than those who did not own a $\operatorname{dog}(M=20.23$ sqrt mins., $S E=0.98$ sqrt mins. $), F(1,640)=35.63, p<.001, \eta^{2}=.053$. Finally, as expected and after controlling for the effects of social desirability, $\beta=.10$, $t(640)=2.73, p<.01$, people who did not own a dog $(M=20.23$ sqrt mins., $S E=0.98$ sqrt mins.) engaged in significantly more total physical activity than dog owners who walked their dog minimally or not at all $(M=13.13$ sqrt mins., $S E=1.09$ sqrt mins. $), F(1$, $640)=23.41, p<.001, \eta^{2}=.035 .^{7}$

\footnotetext{
${ }^{7}$ It should be noted that, dog owners who did and did not walk their dog were combined into one group, following which their physical activity levels were compared to those of non-owners. Results revealed that dog owners engaged in significantly more total time walking for leisure than people who did not own a dog, $F(1,640)=136.70, p<.001, \eta^{2}=$
} 
Taken together, these findings reveal that dog walkers not only engaged in more walking for leisure compared to dog owners who walked their dog minimally or not at all and people who did not own a dog, but they also engaged in more total physical activity than these groups. While people who did not own a dog and dog owners who walked their dog minimally or not at all did not differ in the amount of time they spent walking for leisure, people who did not own a dog were more physically active overall than dog owners who walked their dog minimally or not at all.

Hypotheses regarding physical activity other than dog walking. To determine whether dog owners who walked their dog engaged in more total physical activity, excluding dog walking, than both dog owners who walked their dog minimally or not at all and people who did not own a dog, time spent dog walking was subtracted from the total physical activity scores of dog walkers. Two nonorthogonal planned comparisons, with a Bonferonni corrected alpha of .025 , were then conducted to compare the physical activity scores of the three groups.

It was expected that, once minutes dog walking were removed, dog owners who walked their dog would not differ in their total physical activity over the course of a week compared to people who walked their dog minimally or not at all and people who did not own a dog. Contrary to expectations, and after controlling for the effects of sex, $\beta=-.10$, $t(633)=-2.55, p<.05$, marital status, $\beta=-.13, t(633)=-3.34, p<.01$, and social desirability, $\beta=.12, t(633)=3.16, p<.01, \operatorname{dog}$ owners who walked their $\operatorname{dog}(M=17.09$

.176. In addition, dog owners engaged in significantly more total physical activity than people who did not own a dog, $F(1,643)=16.41, p<.001, \eta^{2}=.025$. 
squrt mins., $S E=0.46$ sqrt mins.) engaged in significantly more total physical activity independent of dog walking than dog owners who walked their dog minimally or not at all $(M=13.51$ sqrt mins., $S E=1.20$ sqrt mins. $), F(1,633)=7.75, p<.01, \eta^{2}=.012$. Also contrary to expectations, after controlling for the effects of social desirability, $\beta=$ $.12, t(637)=3.07, p<.01$, dog owners who walked their $\operatorname{dog}(M=16.80$ sqrt mins., $S E=$ 0.47 sqrt mins.) engaged in significantly less total physical activity independent of dog walking than people who did not own a $\operatorname{dog}(M=20.24$ sqrt mins., $S E=1.09$ sqrt mins.), $F(1,637)=8.38, p<.01, \eta^{2}=.013 .^{8}$

In summary, these findings indicate that it was because of minutes dog walking that dog walkers were more active overall compared to people who did not own a dog, given that when minutes dog walking were excluded, dog walkers were less physically active overall compared to people who did not own a dog. On the other hand, dog owners who did not walk their dog engaged in considerably less overall physical activity; even when minutes dog walking were excluded, they were still less physically active compared to dog walkers.

Hypotheses regarding physical and psychological health. Three nonorthogonal planned comparisons were conducted to examine the effects of group membership on

\footnotetext{
${ }^{8}$ When the amount of time participants engaged in non-walking physical activity was examined, people who did not own a dog engaged in significantly more non-walking physical activity than dog owners who walked their dog minimally or not at all, $F(1,157)$ $=5.53, p<.05, \eta^{2}=.034$. People who did not own a dog and dog owners who walked their dog did not differ in terms of their non-walking physical activity, $F(1,568)=.58$, $\mathrm{ns}, \eta^{2}=.001$. Finally, dog owners who walked their dog engaged in significantly more non-walking physical activity than dog owners who walked their dog minimally or not at all, $F(1,551)=4.46, p<.05, \eta^{2}=.008$.
} 
participants' physical and psychological health scores, using a Bonferonni corrected alpha of .017 for each criterion variable. For these analyses, because people who are married or living with a partner have better health than other groups of people (Opana, 2008), participants' marital status was dichotomized as single/separated/ divorced/widowed versus married/live with partner and considered as a potential covariate. In these analyses, participants' Perceived Stress Scale scores, whether the participant had experienced a traumatic event, minutes spent in nature and time spent on non-dog walking physical activity were included as covariates if they were correlated with the criterion variable. Finally, when planned comparisons were conducted between the dog owning groups, years of dog ownership and level of attachment to their dog, two variables which are known to affect human health, were included if they correlated with the criterion variable. ${ }^{9}$

It was hypothesized that dog owners who walked their dog would have better physical and psychological health than dog owners who walked their dog minimally or not at all. As expected, and after controlling for the effects of sex, $\beta=.06, t(606)=1.49$, ns, age, $\beta=.22, t(606)=5.41, p<.001$, education, $\beta=-.12, t(606)=-3.00, p<.01$, attachment to their $\operatorname{dog}, \beta=.29, t(606)=4.07, p<.001$, experiencing a traumatic event, $\beta=.07, t(606)=1.72$, ns, and social desirability, $\beta=-.13, t(606)=-3.33, p<.01$,

\footnotetext{
${ }^{9}$ While the social support, opportunity to nurture and stress buffer scales predicted overall psychological and/or physical health, given that multicollinearity was a problem among these scales and they correlated with the attachment to dog scale (another control variable that was a stronger predictor of overall physical and psychological health), these three scales were not included in the analyses.
} 
dog owners who walked their $\operatorname{dog}(M=1.09, S E=0.01)$ had significantly better physical health than dog owners who walked their dog minimally or not at all, $(M=1.21, S E=$ $0.03), F(1,606)=11.41, p<.01, \eta^{2}=.018$. Similarly, after controlling for $\operatorname{sex} \beta=.02$, $t(590)=.52$, ns, age, $\beta=-.02, t(590)=-.64, \mathrm{~ns}$, marital status, $\beta=-.07, t(590)=-2.01, p$ $<.05$, education, $\beta=-.06, t(590)=-1.81$, ns, income, $\beta=-.14, t(590)=-3.59, p<.001$, attachment to their dog, $\beta=.32, t(590)=4.85, p<.001$, time spent in nature, $\beta=-.07$, $t(590)=-2.04, p<.05$, and social desirability, $\beta=-.37, t(590)=-10.23, p<.001, \operatorname{dog}$ owners who walked their $\operatorname{dog}(M=1.16, S E=0.02)$ had significantly better psychological health compared to dog owners who walked their dog minimally or not at all $(M=1.29, S E=0.04), F(1,590)=9.69, p<.01, \eta^{2}=.016$.

Second, it was hypothesized that dog owners who walked their dog would have better physical and psychological health than people who did not own a dog. Contrary to expectations, after controlling for the effects of stress, $\beta=.25, t(636)=6.08, p<.001$, experiencing a traumatic event, $\beta=.07, t(636)=1.97, p<.05$, and social desirability, $\beta=$ $.01, t(636)=.14, \mathrm{~ns}, \operatorname{dog}$ owners who walked their $\operatorname{dog}(M=1.18, S E=0.01)$ had significantly poorer physical health than people who did not own a $\operatorname{dog}(M=1.08, S E=$ $0.03), F(1,636)=8.58, p<.01, \eta^{2}=.013$. Also contrary to expectations, after controlling for the effects of stress, $\beta=.76, t(651)=31.09, p<.001$, and social desirability, $\beta=-.12, t(651)=-4.84, p<.001$, dog owners who walked their $\operatorname{dog}(M=$ $1.27, S E=0.01)$ and people who did not own a $\operatorname{dog}(M=1.29, S E=0.02)$ did not differ in psychological health, $F(1,651)=.53, \mathrm{~ns}, \eta^{2}=.001$. 
It was hypothesized that people who did not own a dog would have better physical and psychological health than dog owners who walked their dog minimally or not at all. As hypothesized, after controlling for the effects of age, $\beta=.23, t(623)=5.77$, $p<.001$, stress, $\beta=.29, t(623)=6.99, p<.001$, experiencing a traumatic event, $\beta=.06$, $t(623)=1.62$, ns, and social desirability, $\beta=-.04, t(623)=-.97$, ns, people who did not own a $\operatorname{dog}(M=1.10, S E=0.03)$ had significantly better physical health than dog owners who walked their dog minimally or not at all $(M=1.26, S E=0.03), F(1,623)=12.97, p$ $<.001, \eta^{2}=.020$. However, this finding did not extend to psychological health in that after controlling for the effects of age, $\beta=.01, t(607)=.35$, ns, marital status, $\beta=-.02$, $t(607)=-1.00$, ns, income, $\beta=-.09, t(607)=-3.41, p<.01$, stress, $\beta=.74, t(607)=$ $24.84, p<.001$, time in nature, $\beta=-.03, t(607)=-1.50, \mathrm{~ns}$, and social desirability, $\beta=-$ $.11, t(607)=-4.48, p<.001$, people who did not own a dog $(M=1.29, S E=0.02)$ and dog owners who walked their dog minimally or not at all $(M=1.32, S E=0.03)$ did not differ in psychological health, $F(1,607)=.80$, ns, $\eta^{2}=.001$.

These findings highlight the fact that among dog owners, those who walked their dog had better physical and psychological health than those who walked their dog minimally or not at all. However, people who did not own a dog had better physical health compared to those who did and did not walk their dog, while people who did not own a dog did not differ in their psychological health from either of the dog owning groups.

Relations between time dog walking and well-being. Hierarchical regression analyses were conducted to examine whether dog owners' physical and psychological 
health improved as they spent more time walking their dog over the course of a week. For these analyses, because people who are married or living with a partner have better health than other groups of people (Opana, 2008), participants' marital status was dichotomized as single/separated/divorced/widowed versus married/live with partner and considered as a potential covariate. In these analyses participants' Perceived Stress Scale scores, whether the participant had experienced a traumatic event, minutes spent in nature, time spent on non-dog walking physical activity, years of dog ownership and level of attachment to their dog were included as covariates if they correlated with the criterion variable.

As shown in Table 12, after controlling for the effects of education, attachment to their dog and experiencing a traumatic event, more time spent dog walking in the past week was associated with slightly better physical health, $\beta=-.15, p<.01 .^{10}$

\footnotetext{
${ }^{10}$ One influential case identified through Cook's Distance was deleted from the regression model.
} 
Table 12.

Results of the Hierarchical Regression of the Physical Health of Dog Owners Who Walk Their Dogs $(n=460)$ onto Covariates and Minutes Dog Walking

\begin{tabular}{|c|c|c|c|c|}
\hline Variable & $F_{\text {change }}$ & $d f$ & $\mathrm{R}_{\text {change }}^{2}$ & $\beta$ \\
\hline Step 1 & $8.26^{* * *}$ & 456 & .05 & \\
\hline Education $^{\mathrm{a}}$ & & & & $-.12 * *$ \\
\hline Attachment to dog & & & & $.14^{* *}$ \\
\hline Traumatic event $^{\mathrm{b}}$ & & & & .08 \\
\hline Step 2 & $10.37 * *$ & 455 & .02 & \\
\hline Minutes dog walking & & & & $-.15 * *$ \\
\hline
\end{tabular}

${ }^{a}$ Dummy coded $(0=$ no university, $1=$ at least some university)

${ }^{\mathrm{b}}$ Dummy coded $(0=$ no traumatic event in past month, $1=$ traumatic event in past month) $* * p<.01 . * * * p<.001$

With respect to psychological health, and as shown in Table 13, after controlling for the effects of sex, marital status, education, income, attachment to their dog and experiencing a traumatic event, more time dog walking in the past week was associated with slightly better psychological health, $\beta=-.16, p<.001$. In summary, based on these regression analyses, it is apparent that there are physical and psychological health benefits associated with increased amounts of dog walking. 
Table 13.

Results of the Hierarchical Regression of the Psychological Health of Dog Owners

Who Walk Their Dogs $(n=451)$ onto Covariates and Minutes Dog Walking

\begin{tabular}{|c|c|c|c|c|}
\hline Variable & $F_{\text {change }}$ & $d f$ & $\mathrm{R}_{\text {change }}^{2}$ & $\beta$ \\
\hline Step 1 & $11.14 * * *$ & 444 & .13 & \\
\hline $\operatorname{Sex}^{\mathrm{a}}$ & & & & .05 \\
\hline Marital status $^{\mathrm{b}}$ & & & & -.05 \\
\hline Education $^{\mathrm{c}}$ & & & & -.03 \\
\hline Income $^{d}$ & & & & $-.21 * * *$ \\
\hline Attachment to dog & & & & $.21 * * *$ \\
\hline Traumatic event $\mathrm{e}^{\mathrm{e}}$ & & & & .05 \\
\hline Step 2 & $13.29 * * *$ & 443 & .03 & \\
\hline Minutes dog walking & & & & $-.16 * * *$ \\
\hline
\end{tabular}

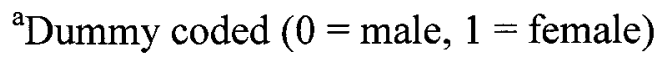

${ }^{\mathrm{b}}$ Dummy coded $(0=$ single/separated/divorced/widowed, $1=$ married/live with partner $)$

${ }^{c}$ Dummy coded $(0=$ no university, $1=$ at least some university $)$

${ }^{\mathrm{d}}$ Dummy coded $(0=$ less than $\$ 35,000,1=\$ 35,000$ or more $)$

${ }^{\mathrm{e}}$ Dummy coded $(0=$ no traumatic event in past month, $1=$ traumatic event in past month) $* * * p<.001$.

\section{Additional Analyses}

Additional analyses were conducted to identify any confounded variables that might provide alternative explanations for the observed significant relations. 
Specifically, for any significant results, potential covariates that correlated with both the predictor and criterion variable were identified as potential confounds. Following which, analyses (i.e., planned comparisons and regression analyses) were repeated controlling for the effects of the potential confound. Using this approach, one confound that might provide an alternative explanation was identified. When psychological health was the criterion variable, for the planned comparison between dog owners who did and did not walk their dog, stress correlated with both the planned comparison and the criterion variable. Stress provided an alternative explanation, given that the planned comparison between dog owners who did and did not walk their dog became nonsignificant after controlling for stress, $F(1,588)=1.58$, ns. Therefore, the observed relationship that dog owners who walked their dog had better psychological health than dog owners who did not walk their dog was an artefact of the fact that stress correlated with both the planned comparison and the criterion variable. 


\section{Discrussion}

The purpose of the present study was to examine the physical activity and health of dog owners who walked their dog, dog owners who walked their dog minimally or not at all and people who did not own a dog in order to assess whether owning a dog is particularly beneficial for dog owners who walk their dog. This study was also designed to assess whether dog owners' physical and psychological health improves as a function of the amount of time they spend walking their dog.

\section{Physical Activity Levels}

Two types of physical activity were considered in the present study, namely the time spent walking for leisure and the time engaged in both walking and non-walking physical activity. As hypothesized, dog owners who walked their dog spent more time walking for leisure than both dog owners who walked their dog minimally or not at all and people who did not own a dog. Specifically, dog owners who walked their dog engaged in 383 additional minutes of leisure walking over the course of a week compared to dog owners who walked their dog minimally or not at all and 339 additional minutes of leisure walking compared to people who did not own a dog. These findings are consistent with both Cutt et al.'s (2008a) finding regarding Australians who did and did not walk their dog and Bauman et al.'s (2001) comparison of Australians who walked their dog for more than a minimal amount of time with Australians who did not own a dog. However, contrary to expectations and unlike Bauman et al., people who did not own a dog and dog owners who walked their dog minimally or not at all spent equal amounts of time walking for leisure over the course of a week. 
The analyses of overall physical activity indicated that, as hypothesized, dog owners who walked their dog spent more time engaged in physical activity over the course of a week than both dog owners who walked their dog minimally or not at all and people who did not own a dog. Consistent with the findings of previous research (Bauman et al., 2001; Cutt et al., 2008a), dog owners who walked their dog engaged in 556 more minutes of physical activity than dog owners who walked their dog minimally or not at all and 315 more minutes of physical activity than people who did not own a dog. Also as expected, people who did not own a dog engaged in more total physical activity than dog owners who walked their dog minimally or not at all. Finally, people who did not own a dog engaged in 241 more minutes of physical activity than dog owners who walked their dog minimally or not at all, a finding that is consistent with Bauman et al.'s (2001) study.

It is noteworthy that only dog walkers satisfy the Surgeon General's recommended 150 minutes of physical activity per week (U.S. Department of Health and Human Services, 1996) when the time they spent walking for leisure is considered. In contrast, all three groups exceeded the minimum activity recommendation when total physical activity levels are examined. Specifically, dog owners who walked their dog exceeded the guideline by 656 minutes, people who did not own a dog by 341 minutes, and dog owners who walked their dog minimally or not at all by 100 minutes. Together, these findings suggest that people who did not own a dog and dog owners who walked their dog minimally or not at all may have engaged in equal amounts of leisure walking because people who did not own a dog spent more time engaged in non-walking physical 
activity. Indeed, examining this possibility revealed that people who did not own a dog engaged in 75.81 more minutes of non-walking physical activity (e.g., soccer, bicycling, dance class) than dog owners who walked their dog minimally or not at all.

Minutes dog walking were subtracted from dog walkers' total physical activity scores in order to determine whether time spent dog walking was responsible for the greater amount of physical activity among dog walkers compared to both people who did not own a dog and dog owners who walked their dog minimally or not at all. Contrary to expectations, after controlling for the time spent dog walking, dog walkers engaged in 91 minutes less physical activity than people who did not own a dog. This finding suggests that dog owners who walk their dog are choosing to spend a considerable amount of time dog walking and that they are more physically active than people who do not own a dog because of the time they spend dog walking. One possibility is that, after acquiring a dog, people find that dog walking is a pleasurable activity and subsequently spend a considerable amount of time dog walking. Moreover, dog walking may be an especially appealing form of physical activity for some dog owners because it is inexpensive (Nelson \& Folta, 2009), can be done year round, and is associated with little risk of injury (U.S. Department of Health and Human Services, 2008).

Also unexpected was the finding that dog walkers engaged in 150 more minutes of physical activity than dog owners who walked their dog minimally or not at all even after the time spent dog walking was controlled. This finding differs from that observed by Cutt et al. (2008a) where, after minutes dog walking were subtracted from dog walkers' total minutes of physical activity, Australian dog walkers engaged in only 11.8 
more minutes of weekly physical activity than people who did not walk their dog. This finding highlights the fact that dog owners who choose to walk their dog are considerably more active than those who walk their dog minimally or not at all.

To date, researchers have typically grouped dog owners who do and do not walk their dog together and then compared the time they spend engaged in walking and other physical activities with that of people who do not own a dog (Brown \& Rhodes, 2006; Cutt et al., 2008b, 2008d; Dembicki \& Anderson, 1996; Giles-Corti \& Donovan, 2003; Headey, 1999; Headey \& Zheng, 2007; Rogers et al., 1993; Thorpe et al., 2006a). In contrast, this study compared the physical activity levels of dog owners who walked their dog for periods lasting at least 10 minutes, dog owners who walked their dog minimally (i.e., for periods lasting less than 10 minutes) or not at all, and people who did not own a dog. However, when the dog owners who did and did not walk their dog in the present study were collapsed into one group, dog owners spent more time engaged in both walking for leisure and total physical activity than people who did not own a dog. These conclusions would have been misleading given that people who walked their dog minimally or not at all engaged in an equal amount of leisure walking, but less total physical activity, than people who did not own a dog. These findings highlight the need to consider differences in the amount of time spent dog walking when examining dog owners' physical activity levels.

\section{Physical and Psychological Health}

The findings of the comparisons of the physical and psychological well-being of dog walkers, dog owners who walked their dog minimally or not at all and people 
without a dog were mixed. Consistent with expectations, dog walkers had better physical health than dog owners who walked their dog minimally or not at all. Also as hypothesized, people who did not own a dog had better physical health than dog owners who walked their dog minimally or not at all. Surprisingly however, people who did not own a dog had better physical health than dog walkers and the same psychological health as both dog owners who walked their dog and dog owners who walked their dog minimally or not at all. In the case of psychological health, level of stress provided an alternative explanation for the finding that dog owners who walked their dog had better psychological health than dog owners who walked their dog minimally or not at all.

That dog owners who walked their dog had better physical health than dog owners who walked their dog minimally or not at all is entirely consistent with the dramatic differences in the amount of time these groups spent walking for leisure and engaged in overall physical activity. Specifically, dog walkers engaged in 6.3 times more leisure walking (383 additional minutes) and 3.2 times more overall physical activity (556 additional minutes) than dog owners who did not walk their dog. Similarly, that people who did not own a dog had better physical health than dog owners who did not walk their dog is not surprising given that people who did not own a dog engaged in 2 times more total physical activity (241 additional minutes) than people who did not walk their dog.

Contrary to expectations, the relationship between dog owners who did and did not walk their dog and psychological health was not direct, but rather was affected by level of stress. Dog owners who walked their dog had lower levels of stress and lower 
levels of stress were associated with better psychological health. It is speculated that dog walking may help dog owners relax, which may help them feel more positive, better able to cope with life's challenges and, subsequently, less stressed. Support for this contention is provided by Lacey's (2004) finding that, as the number of minutes dog walking increased, stress levels decreased. Alternatively, it is possible that the difference in the stress level of dog owners who do and do not walk their dog may be due to other factors. As an example, it is possible that, unlike dog walkers, dog owners who do not walk their dog may have higher levels of stress because they have demanding jobs and limited leisure time.

What is surprising is that dog walkers, who engaged in 1.6 times more total physical activity than people who did not own a dog (i.e., 315 additional minutes in a week), had poorer physical health than people who did not own a dog. Conceivably, this physical health difference may be due to the fact that when time spent dog walking was excluded, non-dog owners engaged in more minutes of physical activity than dog walkers. In addition to receiving 150 minutes of aerobic physical activity per week, both the United States Surgeon General (U.S. Department of Health and Human Services, 1996) and the updated recommendations from the American College of Sports Medicine and the American Heart Association (Haskell et al., 2007) recommend that adults engage in muscle strengthening activities, such as weight training, at least two times a week. It is possible that people who did not own a dog had better physical health than dog owners because the additional time they spent in non-dog walking physical activities included both muscle strengthening and aerobic physical activities. 
Although dog walkers engaged in more total physical activity than people who did not own a dog, they may have received fewer physical health benefits from dog walking if they did not walk their dog at a moderate pace. Both the United States Surgeon General (U.S. Department of Health and Human Services, 1996) and the updated recommendations of the American College of Sports Medicine and the American Heart Association (Haskell et al., 2007) recommend at least 150 minutes of moderate physical activity. However, in the present study $12 \%(n=59)$ of the dog walkers indicated that they typically walked their dog at a slow pace. This may have occurred if the dog was small or elderly or if the owner was elderly. In addition, the benefits of dog walking may have been reduced if dog owners stopped and started throughout their walks. Messent (1983) found that, when dog owners walked the same route with and without their dog, they took longer when they were accompanied by their dog. He suggests that the difference may be due to the added diversions, such as the dog stopping to play with other dogs, to explore its surroundings, and to toilet, as well as the dog owner stopping to socialize with other dog owners. Although the participants in the present study were explicitly instructed not to include periods of time during which they stood still while walking their dog, it is possible that dog owners only excluded lengthy periods of standing still. Thus, walking at a slow pace and stopping and starting during their walks may go some way to explaining why dog walkers had poorer physical health than people who did not own a dog.

Also noteworthy with respect to physical health is that, based on Heath Canada's (2003) classification for BMI, both dog walkers and people who walked their dog 
minimally or mot at all were classified as overweight, while people who did not own a dog were classified as normal weight. As Cutt et al. (2008d) note, there is an ongoing debate in the literature as to whether, after acquiring a dog, people become more active or whether active people are more likely to acquire a dog. The findings in the present study may reflect pre-existing differences in the activity levels of people who did not own a dog and dog owners.

With respect to psychological health, it is speculated that the fact that people who did not own a dog did not differ from both dog owners who walked their dog and dog owners who walked their dog minimally or not at all is because the differences in the overall physical activity levels of the groups were not large enough to affect their psychological health. Specifically, the difference in the number of minutes of overall physical activity between people who did not own a dog and dog owners who walked their dog was 315 minutes, while the difference between people who did not own a dog and dog owners who walked their dog minimally was 241 minutes. Because the three groups all had levels of physical activity in excess of the Surgeon General's guideline, it is likely that they all received psychological health benefits from their physical activity. It should be noted that, although researchers have found that it is beneficial for health to exceed the minimum guideline of 150 minutes of physical activity per week, additional research is still needed because researchers have not yet established the "point of maximum benefit for most health benefits" (Haskell et al., 2007, p. 4).

\section{Dog Walkers' Physical and Psychological Health}

As noted earlier, the current study was also designed to assess whether dog 
owners' physical and psychological health improves as a function of the amount of time they spend walking their dog. In this regard dog walkers' physical and psychological health did indeed improve as the number of minutes spent dog walking over the course of a week for periods of at least 10 minutes increased. Given that researchers have found that physical activity above the minimum requirement of 150 minutes of physical activity is beneficial for physical and psychological health (Haskell et al., 2007; U.S. Department of Health and Human Services, 1996), this finding is not surprising. To date, however, few studies of dog walking have examined this relation (Lacey, 2004; Serpell, 1991) and the findings of those that have are limited in that health was only assessed through measures of stress, minor health problems and a general measure of psychological health. As a result, the current findings, which are based on more comprehensive composite measures of physical and psychological health, provide both further and stronger evidence of the relation between time spent dog walking and physical and psychological health.

\section{Limitations of the Current Research}

Like all research, this research has both strengths and weaknesses. Potentially the most fundamental limitation stems from the cross-sectional and non-experimental nature of the study, and hence the inability to make causal inferences. Given the likely unwillingness of people to be randomly assigned to walk or not walk their dog, it is hoped that future research will be conducted using a longitudinal design.

The self-report nature of the current study is also problematic as participants' estimates of the time they spent walking and exercising may have been inaccurate. In an 
attempt to address these concerns, the physical activity questions were as detailed as possible. For example, participants were asked to specify the amount of time they spent walking for leisure on each day during the past week rather than providing one estimate of the time they spent walking for leisure for the entire past week. Nevertheless, future researchers might endeavour to obtain more accurate measures by, for example, using diary recording or pedometers in a longitudinal study.

In addition to the difficulties of providing accurate data, some participants may have provided socially desirable overestimates of the time they spent engaged in walking or other physical activities and they may have reported their physical and psychological health as being better than it was. Fortunately, the participants in the present study completed the Marlowe-Crowne Social Desirability Scale (Reynolds, 1982) and the analyses indicated that social desirability did not account for any of the findings.

Other limitations stem from the characteristics of the participants. Most notably, there were unequal numbers of females and males; approximately $80 \%$ of the sample was female. As a result, it was not possible to examine the main or moderating effects of participants' gender. Furthermore, the sample was not representative of the Canadian population, as it included a disproportionate number of well-educated participants. Approximately forty percent of the participants in the present study had one or more university degrees compared to only $23 \%$ of the Canadian population 25 to 64 years of age (Statistics Canada, 2008b). Given that researchers have found that, as level of education increases, physical activity (Cameron, Craig, Stephens, \& Ready, 2002) and health (Tremblay, Ross, \& Berthelot, 2002) improve, it may be that participants in the 
present study exercised more and were healthier than the Canadian population as a whole.

A final limitation of the present study stems from the fact that the data were not collected throughout the year. Participants completed the survey during the months of August to mid November, when it was not unpleasantly hot or cold. It is likely that the number of minutes participants reported dog walking would have been considerably lower if the data had been collected during the winter months.

\section{Future Research}

As noted above, there is a need for additional longitudinal research that builds on the longitudinal research of both Serpell (1991) and Cutt et al. (2008d). In addition to the advantages noted above, such research would make it possible to determine whether more active people acquire dogs or whether people become more active after they acquire a dog.

The indirect effects of dog walking on people's health also merit investigation. For example, dog owners who spend more time dog walking are also likely to benefit from the social catalyst effect, which refers to the increase in the number of humanhuman interactions that dog owners experience when they are accompanied by their dog rather than alone (McNicholas \& Collis, 2000; Messent, 1983; Wells, 2004). Further, in a participant observation study Robins, Sanders, and Cahill (1991) found that previously unacquainted dog walkers developed friendships and regular walking groups. As a result of the social catalyst effect, dog owners may increase their social networks and this may, in turn, facilitate dog owners' physical and psychological health (McNicholas \& Collis, 2000; Wells, 2004). Conceivably, the dog owners in the present study who spent more 
time dog walking engaged in more social interaction. If so, social interaction may have been responsible for some of the health benefits attributed to dog walking in the present study.

The benefits of dog walking for the health of dog walkers may also be mediated by the amount of time spent dog walking in nature. Specifically, as dog walkers spend more time dog walking, they are probably more likely to spend at least some of their time walking in a natural environment such as a park or a forest. And this too may enhance their well-being. For example, Godbey, Graefe, and James (1992) found that people who frequently visited local parks were more likely to describe their health as 'excellent,' while people who did not use local parks were more likely to say that their health was 'fair' or 'poor.' In addition, Grahn and Stigsdotter (2003) found that people who frequently spent time in nature were less stressed. Other studies have found that people's psychological health is better when they leave a natural environment relative to when they first entered it, as indicated by reduced levels of anxiety, scepticism, anger, and aggression and increased levels of happiness and positive affect (Hartig, Mang, \& Evans, 1991; Hull \& Michael, 1995; More \& Payne, 1978). Given the health benefits of being in nature, then, it may be useful to examine whether dog walkers' receive additional physical and psychological health benefits as they spend more time walking their dogs in nature.

More fundamentally, future research might examine whether people who do and do not walk their dog acquire their dog for different reasons. The reasons why people decide to acquire a dog could be assessed before individuals acquire their dog, in order to 
explore the possibility that people who later do and do not walk their dog differ in their reasons for acquiring a dog. For example, dog owners who walk their dog may have acquired a dog for exercise, while dog owners who do not walk their dog may have acquired it because their children persuaded them to do so.

It is noteworthy that $17.4 \%$ of the variance in the total physical activity levels of dog owners could be explained by whether dog owners did or did not walk their dog. Given that dog walkers had better physical health than dog owners who walked their dog minimally or not at all, additional research is needed to explore why some dog owners do not walk their dog. Cutt et al. (2008a) found that people who did and did not walk their dog differed on various dog-related factors (e.g., dog owners were more likely to walk their dog if they perceived their dog as a source of motivation and social support for walking) and cognitive factors (e.g., dog owners were more likely to walk their dog if family members, other dog owners or veterinarians had positive beliefs about daily dog walking). In another study, Cutt, Giles-Corti, Wood, Knuiman, and Burke (2008c) found that various social (e.g., the presence of other dogs with inadequate training) and physical environmental factors (e.g., the [un]availability and quality of public open spaces) acted as barriers to dog walking. A good number of other factors may also be involved. For example, people with less leisure time and those with large, fenced backyards may be less likely to walk their dog. There may also be gender differences in who walks a dog. Relevant here are the findings of Suminski (2005), which indicated that women who believed their neighbourhood safety was average were 3.3 times more likely to walk their dog compared to women who believed their neighbourhood safety was below average. 
Given the host of factors that may be involved, a qualitative interview study might be a good way of gaining insight into the reasons some dog owners do not walk their dog.

\section{Conclusion}

While previous research, with few exceptions (Bauman et al., 2001; Cutt et al., 2008a; Schofield et al., 2005), has tended to treat dog owners as if they were a homogeneous group, the findings of the present study highlight the heterogeneous nature of this group. Indeed, in the present study not all dog owners were more physically active than people who did not own a dog. Instead, a subgroup of dog owners was most active, namely dog owners who walked their dog. Also noteworthy is that dog owners who did not walk their dog did not compensate for not doing so by spending more time engaged in other types of physical activity. To the contrary, dog owners who did not walk their dog were the least active in all respects.

People who did not own a dog had better physical, but not psychological, health than both dog walkers and dog owners who walked their dog minimally or not at all and, among dog owners, people who walked their dog for adequate periods of time had better physical and psychological health than dog owners who walked their dog minimally or not at all. While the former finding was an unanticipated surprise, the latter finding illustrates the need for researchers to consider the extent to which dog owners walk their dogs. Moreover, that dog walkers had better physical health than dog owners who walked their dog minimally or not at all suggests that convincing all dog owners to walk their dog for adequate periods of time might enhance dog owners' health and result in healthcare savings. Further, the observed positive relations between the time dog owners 
spent walking their dog and their physical and psychological health suggests that urban planners might usefully identify ways of providing dog-friendly walking environments that encourage dog owners to spend more time walking their dog. 


\section{References}

Adéll-Båth, M., Krook, A. C., Sandqvist, G., \& Skantze, K. (1979). Do we need dogs?: A study of dog's social significance to man. Gothenburg, Sweden: University of Gothenburg Press.

Akiyama, H., Holtzman, J. M., \& Britz, W. E. (1986). Pet ownership and health status during bereavement. Omega: Journal of Death and Dying, 17, 87-93.

Allen, K., Blascovich, J., \& Mendes, W. B. (2002). Cardiovascular reactivity and the presence of pets, friends, and spouses: The truth about cats and dogs. Psychosomatic Medicine, 64, 727-739.

American Pet Products Manufacturers Association. (2008). Industry statistics \& trends. Retrieved April 14, 2008 from http://www.appma.org/press_industrytrends.asp

Anderson, W. P., Reid, C. M., \& Jennings, G. L. (1992). Pet ownership and risk factors for cardiovascular disease. The Medical Journal of Australia, 157, 298-301.

Bauman, A. E., Russell, S. J., Furber, S. E., \& Dobson, A. J. (2001). The epidemiology of dog walking: An unmet need for human and canine health. Medical Journal of Australia, 175, 632-634.

Bonas, S., McNicholas, J., \& Collis, G. M. (2000). Pets in the network of family relationships: An empirical study. In A. L. Podberscek, E. S. Paul \& J. A. Serpell (Eds.), Companion animals \& us: Exploring the relationships between people \& pets (pp. 209-236). New York: Cambridge University Press.

Brown, S. G., \& Rhodes, R. E. (2006). Relationships among dog ownership and leisuretime walking in Western Canadian adults. American Journal of Preventive 
Medicine, 30,131-136.

Cameron, C., Craig, C., \& Paolin, S. (2005). Local opportunities for physical activity and sport: Trends from 1999 - 2004. Ottawa, ON: Canadian Fitness and Lifestyle Research Institute.

Cavanaugh, L. A., Leonard, H. A., \& Scammon, D. L. (2008). A tail of two personalities: How canine companions shape relationships and well-being. Journal of Business Research, 61, 469-479.

Charnetski, C. J., Riggers, S., \& Brennan, F. X. (2004). Effect of petting a dog on immune system function. Psychological Reports, 95, 1087-1091.

Cohen, $\mathbb{J}_{0}$ (1988). Statistical power analysis for the behavioural sciences (2nd ed.). New Jersey: Lawrence Erlbaum Associates.

Cohen, S., Kamarck, T., \& Mermelstein, R. (1983). A global measure of perceived stress. Journal of Health and Social Behavior, 24, 385-396.

Cutt, H., Giles-Corti, B., \& Knuiman, M. (2008a). Encouraging physical activity through dog walking: Why don't some owners walk with their dog? Preventive Medicine, 46, 120-126.

Cutt, H., Giles-Corti, B., Knuiman, M., Timperio, A., \& Bull, F. (2008b). Understanding dog owners' increased levels of physical activity: Results from RESIDE. American Journal of Public Health, 98, 66-69.

Cutt, H., Giles-Corti, B., Wood, L. J. Knuiman, M., \& Burke, V. (2008c). Barriers and motivators for owners walking their dog: Results from qualitative research. Health Promotion Journal of Australia, 19, 118-124. 
Cutt, $\mathbb{H}_{\text {。, }}$ Knuiman, M. W., \& Giles-Corti, B. (2008d). Does getting a dog increase recreational walking? International Journal of Behavioral Nutrition and Physical Activity, 5. Retrieved April 29, 2008, from http://www.ijbnpa.org/content/pdf/1479-5868-5-17.pdf

Dembicki, D., \& Anderson, J. (1996). Pet ownership may be a factor in improved health of the elderly. Journal of Nutrition for the Elderly, 15, 15-31.

Dotson, M. J., \& Hyatt, E. M. (2008). Understanding dog-human companionship. Journal of Business Research, 61, 457-466.

Enders-Slegers, M. (2000). The meaning of companion animals: Qualitative analysis of the life histories of elderly cat and dog owners. In A. L. Podberscek, E. S. Paul \& J. A. Serpell (Eds.), Companion animals \& us: Exploring the relationships between people \& pets (pp. 237-256). New York: Cambridge University Press.

Friedmann, E., Katcher, A. H., Lynch, J. J., \& Thomas, S. A. (1980). Animal companions and one-year survival of patients after discharge from a coronary care unit. Public Health Reports, 95, 307-312.

Friedmann, E., \& Thomas, S. A. (1995). Pet ownership, social support, and one-year survival after Acute Myocardial Infarction in the Cardiac Arrhythmia Suppression Trial (CAST). American Journal of Cardiology, 76, 1213-1217.

Giles-Corti, B. \& Donovan, R. J. (2003). Relative influences of individual, social environmental, and physical environmental correlates of walking. American Journal of Public Health, 93, 1583-1589.

Gilmour, H. (2007). Physically active Canadians. Health Reports, 18, 45-65. 
Godbey, G., Graefe, A. R., \& James, S. W. (1992). The benefits of local recreation and park services. Pennsylvania: National Recreation and Park Association.

Goldmeier, J. (1986). Pets or people: Another research note. The Gerontologist, 26, 203-206.

Grahn, P., \& Stigsdotter, U. A. (2003). Landscape planning and stress. Urban Forestry \& Urban Greening, 210, 1-18.

Ham, S. A., \& Epping, J. E. (2006). Dog walking and physical activity in the United States. Preventing Chronic Disease, 3, 1-7.

Hartig, H., Mang, M., \& Evans, G. W. (1991). Restorative effects of natural environment experiences. Environment and Behovior, 23, 2-26.

Haskell, W. L., Lee, I. M., Pate, R. R., Powell, K. E., Blair, S. N., Franklin, B. A., et al. (2007). Physical activity and public health. Updated recommendations for adults from the American College of Sports Medicine and the American Heart Association. Circulation, 116, 1081-1093.

Headey, B. (1999). Health benefits and health cost savings due to pets: Preliminary estimates from an Australian National Survey. Social Indicators Research, 47, $233-243$

Headey, B., \& Grabka, M. M. (2007). Pets and human health in Germany and Australia: National longitudinal results. Social Indicators Research, 80, 297-311.

Headey, B., Na, F., \& Zheng, R. (2007). Pet dogs benefit owners' health: A 'natural experiment' in China. Social Indicators Research. Retrieved October 28, 2007, from 
http://springerlink, metapress.com.proxy.library.carleton.ca/content/rq1 p59556h21 8p64/fulltext.pdf

Health Canada. (2003). Canadian guidelines for body weight classification in adults (Cat. No. H49-179/2003E). Ottawa: Minister of Public Works and Government Services Canada.

Health Canada and the Canadian Society for Exercise Physiology. (1998). Canada's physical activity guide to healthy active living (Cat. No. H39-429/1998-1E). Ottawa: Health Canada.

Hecht, L., McMillin, J. D., \& Silverman, P. (2001). Pets, networks and well-being. Anthrozoös, 14, 95-108.

Herrald, M. M., Tomaka, J., \& Medina, A. Y. (2002). Pet ownership predicts adherence to cardiovascular rehabilitation. Journal of Applied Social Psychology, 32, 11071123.

Holbrook, M. B., Stephens, D. L., Day, E., Holbrook, S. M., \& Strazar, G. (2001). A collective stereographic photo essay on key aspects of animal companionship: The truth about dogs and cats. Academy of Marketing Science Review. Retrieved May 10, 2008, from http://www.amsreview.org/articles/holbrook01-2001.pdf

Hull, R. B., \& Michael, S. E. (1995). Nature-based recreation, mood change, and stress restoration. Leisure Science, 17, 1-14.

Johnson, R. A., \& Meadows, R. L. (2002). Older Latinos, pets, and health. Western Journal of Nursing Research, 24, 609-620.

Katzmarkzyk, P. T., \& Janseen, I. (2004). The economic costs associated with physical 
inactivity and obesity in Canada. Canadian Journal of Applied Physiology, 29, $90-115$.

Lacey, A. (2004). Effects of dog walking, walking, and pet presence on women's stress levels. Unpublished doctoral dissertation, The Chicago School of Professional Psychology, Chicago, Illinois.

Leger Marketing. (2002). Canadians and their pets. Retrieved April 14, 2008, from http://winmr.com/documents/SPCLM/020617ENG.pdf

More, T. A., \& Payne, B. R. (1978). Affective responses to natural areas near cities. Journal of Leisure Research, 10, 7-12.

McNicholas, I. \& Collis, G. M. (2000). Dogs as catalysts for social interactions: Robustness of the effect. British Journal of Psychology, 91, 61-70.

Messent, P. R. (1983). Social facilitation of contact with other people by pet dogs. In A. H. Katcher \& A. M. Beck (Eds.), New Perspectives on Our Lives with Companion Animals (pp. 37-46). Philadelphia: University of Pennsylvania Press.

Nelson, M. E., \& Folta, S. C. (2009). Further evidence for the benefits of walking. American Journal of Clinical Nutrition, 89, 15-16.

Odendaal, J. S. J. (2000). Animal-assisted therapy—magic or medicine? Journal of Psychosomatic Research, 49, 275-280.

Opana, H. M. (2008). Using the National Population Health Survey to identify factors associated with patterns of psychological distress over 10 years. Healthcare Policy, 3, 56-65.

Quigley, J. S., Vogel, L. E., \& Anderson, R. K. (1983). A study of perceptions and 
attitudes toward pet ownership. In A. H. Katcher \& A. M. Beck (Eds.), New perspectives on our lives with companion animals (pp. 266-275). Philadelphia: University of Pennsylvania Press.

Radloff, L. S. (1977). The CES-D Scale: A self-report depression scale for research in the general population. Applied Psychological Measurement, 1, 385-401.

Raina, P., Waltner-Toews, D., Bonnett, B., Woodward, C., \& Abernathy, T. (1999). Influence of companion animals on the physical and psychological health of older people: An analysis of a one-year longitudinal study. Journal of the American Geriatrics Society, 47, 323-330.

Reynolds, W. M. (1982). Development of reliable and valid short forms of the MarlowCrowne Social Desirability scale. Journal of Clinical Psychology, 38, 119-125.

Roberts, C. A., McBride, E. A., Rosenvinge, H. P., Stevenage, S. V., \& Bradshaw, J. W. S. (1996). The pleasure of a pet: The effect of pet ownership and social support on loneliness and depression in a population of elderly people living in their own homes. In J. Nicholson \& A. Podberscek (Eds.), Further issues in research in companion animal studies (pp. 64). Proceedings of a workshop held at the University of Cambridge by the Society for Companion Animal Studies.

Robins, D. M., Sanders, C. R., \& Cahill, S. E. (1991). Dogs and their people: Petfacilitated interaction in a public setting. Journal of Contemporary Ethnography, 20, 3-25.

Rogers, J., Hart, L. A., \& Boltz, R. P. (1993). The role of pet dogs in casual conversations of elderly adults. The Journal of Social Psychology, 133, 265-277. 
Salmon, P. W., \& Salmon, I. M. (1983). Who owns who?: Psychological research into the human-pet bond in Australia. In A. H. Katcher \& A. M. Beck (Eds.), New perspectives on our lives with companion animals (pp. 244-265). Philadelphia: University of Pennsylvania Press.

Santor, D. A., Zuroff, D. C., Ramsay, J. O., Cervantes, P., \& Palacios, J. (1995). Examining scale discriminability in the BDI and CES-D as a function of depressive severity. Psychological Assessment, 2, 131-139.

Schofield, G., Mummery, K., \& Steele, R. (2005). Dog ownership and human health related physical activity: An epidemiological study. Health Promotion Journal of Australia, 16, 15-19.

Serpell, J. A. (1990). Evidence for long-term effects of pet ownership on human health. In I. H. Burger (Ed.), Waltham Symposium 20. Pets, Benefits and Practice (pp. 17). London: BVA Publications.

Serpell, J. (1991). Beneficial effects of pet ownership on some aspects of human health and behaviour. Journal of the Royal Society of Medicine, 84, 717-720.

Siegel, J. M. (1990). Stressful life events and use of physician services among the elderly: The moderating role of pet ownership. Journal of Personality and Social Psychology, 58, 1081-1086.

Simons, L. A., Simons, J., McCallum, J., \& Friedlander, Y. (2000). Pet ownership is not associated with future health: A nine-year prospective study in older Australians. Australasian Journal of Aging, 19, 139-142.

Slater, M. R., Robinson, L. E., Zoran, D. L., Wallace, K. A., \& Scarlett, J. M. (1995). 
Diet and exercise patterns in pet dogs. Journal of the American Veterinary Medical Association, 207, 186-190.

Spielberger, C. D., Gorsuch, R. L., Lushene, R., Vagg, P. R., \& Jacobs, G. A. (1983).

State-Trait Anxiety Inventory for Adults: Sampler Set, Manual, Test Booklet and Scoring Key. Palo Alto, CA: Mind Garden.

Staats, S., Sears, K., \& Pierfelice, L. (2006). Teachers' pets and why they have them: An investigation of the human animal bond. Journal of Applied Social Psychology, 36, 1881-1891.

Stallones, Marx, Garrity, \& Johnson (1990). Pet ownership and attachment in relation to the health of U.S. adults, 21 to 64 years of age. Anthrozoös, 4, 100-112.

Statistics Canada. (2006a). Canadian Internet Use Survey. Retrieved April 25, 2008 from http://www.statcan.ca/Daily/English/060815/d060815b.htm

Statistics Canada. (2006b). 2006 Census of Population (Catalogue No. 97-563XCB2006014). Ottawa: Statistics Canada.

Statistics Canada. (2008). Educational Portrait of Canada, 2006 Census (Catalogue No. 97-560-X). Ottawa: Statistics Canada.

Suminski, R. R., Poston, W. S. C., Petosa, R. L., Stevens, E., \& Katzenmoyer, L. M. (2005). Features of the neighbourhood environment and walking by U.S. adults. American Journal of Preventive Medicine, 28, 149-155.

Tabachnik, B. G., \& Fidell, L. S. (2007). Using multivariate statistics $\left(5^{\text {th }}\right.$ Ed). Boston: Pearson.

Thorpe, R. J., Kreisle, R. A., Glickman, L. T., Simonsick, E. M., Newmann, A. B., \& 
Kritchevsky, S. (2006a). Physical activity and pet ownership in year 3 of the Health ABC study. Journal of Aging and Physical Activity, 14, 154-169.

Thorpe, R. J., Simonsick, E. M., Brach, J. S., Ayonayon, H., Satterfield, S., Harris, T. B., et al. (2006b). Dog ownership, walking behaviour, and maintained mobility in late life. Journal of the American Geriatrics Society, 54, 1419-1424.

Tower, R. B. \& Nokota, M. (2006). Pet companionship and depression: Results from a United States Internet sample. Anthrozoös, 19, 50-65.

Tremblay, S., Ross, N. A., \& Berthelot, J. M. (2002). Regional socio-economic context and health. Health Reports, 13, 33-44.

U.S. Department of Health and Human Services. (1996). Physical activity and health: A report of the Surgeon General. Atlanta: U.S. Department of Health and Human Services, Centers for Disease Control and Prevention, National Center for Chronic Disease Prevention and Health Promotion.

U.S. Department of Health and Human Services (2008). 2008 Physical Activity Guidelines for Americans. Washington, DC: U.S. Department of Health and Human Services.

Watson, D., Clark, L. A., \& Tellegen, A. (1988). Development and validation of brief measures of positive and negative affect: The PANAS Scales. Journal of Personality and Social Psychology, 54, 1063-1070.

Wells, D. L. (2004). The facilitation of social interactions by domestic dogs. Anthrozoös, 17, 340-353.

Wood, L. J., Giles-Corti, B., Bulsara, M. K., \& Bosch, D. A. (2007). More than a furry 
companion: The ripple effect of companion animals on neighbourhood interactions and sense of community. Society \& Animals, 15, 43-56.

Zasloff, R. L., \& Kidd, A. H. (1994). Loneliness and pet ownership among single women. Psychological Reports, 75, 747-752. 
Dog Walking and Well-Being 86

Appendix A:

Research Materials 


\section{Background Questions}

1) Sex (circle): Male / Female

2) Current age: years old

3) Marital status (tick one):

Single

__ Cohabitating (lived with partner for less than 1 year)

Common-law (lived with partner for 1 or more years)

Married

Separated

__ Divorced

Widowed

4) Country in which currently live (tick one):

Canada

Other Please specify:

5) Do you live alone (circle)? Yes / No

6) Are you currently a full-time university of college student (circle)? Yes / No 
7) What is y@ur mighnest level of edreation? (tick one):

Elementary school

Some high school

Finished high school

Some college

College degree

Some university

One university degree

Two or more university degrees

Other

Please specify:

\section{8) What is your annual income before tax? (tick one)}

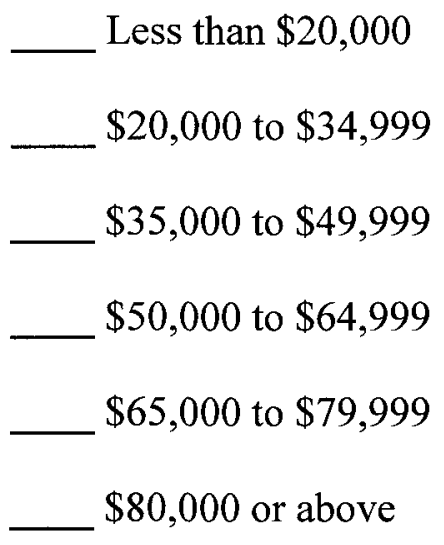




\section{Physierl Actizity Questimes}

When you respond to the two following questions, please answer in a manner similar to the example provided below:

$$
\text { Example } \quad \frac{1}{\text { Hours }} \quad \frac{10}{\text { Minutes }}
$$

1) In the past week, approximately how much time did you spend outdoors in a natural environment (e.g., a park, forest, the countryside). Do not include time spent outdoors on city streets or time spent dog walking.

$$
\overline{\text { Hours }} \overline{\text { Minutes }}
$$

2) Over the past week, how much time did you spend walking for transportation (e.g., walking to work or a store). Do not include periods of less than 10 minutes or time spent walking for transportation with your dog.

Monday

$$
\overline{\text { Hours }} \quad \overline{\text { Minutes }}
$$

Tuesday

$$
\overline{\text { Hours }} \overline{\text { Minutes }}
$$

Wednesday

$$
\overline{\text { Hours }} \overline{\text { Minutes }}
$$

Thursday

$$
\overline{\text { Hours }} \overline{\text { Minutes }}
$$

Friday

$$
\overline{\text { Hours }} \overline{\text { Minutes }}
$$

Saturday

$$
\overline{\text { Hours }} \overline{\text { Minutes }}
$$

Sunday

$\overline{\text { Hours }} \overline{\text { Minutes }}$


3) If you walked for transportation during the past 7 days, in general, how fast was your pace (tick one)?

Slow pace

Moderate pace

Fast/brisk pace

4) Over the past week, excluding walking, how much time did you spend engaged in physical activities for transportation (e.g., bicycling or jogging to get to work or a store). Do not include periods of less than 10 minutes or time spent in an activity for transportation with your dog.

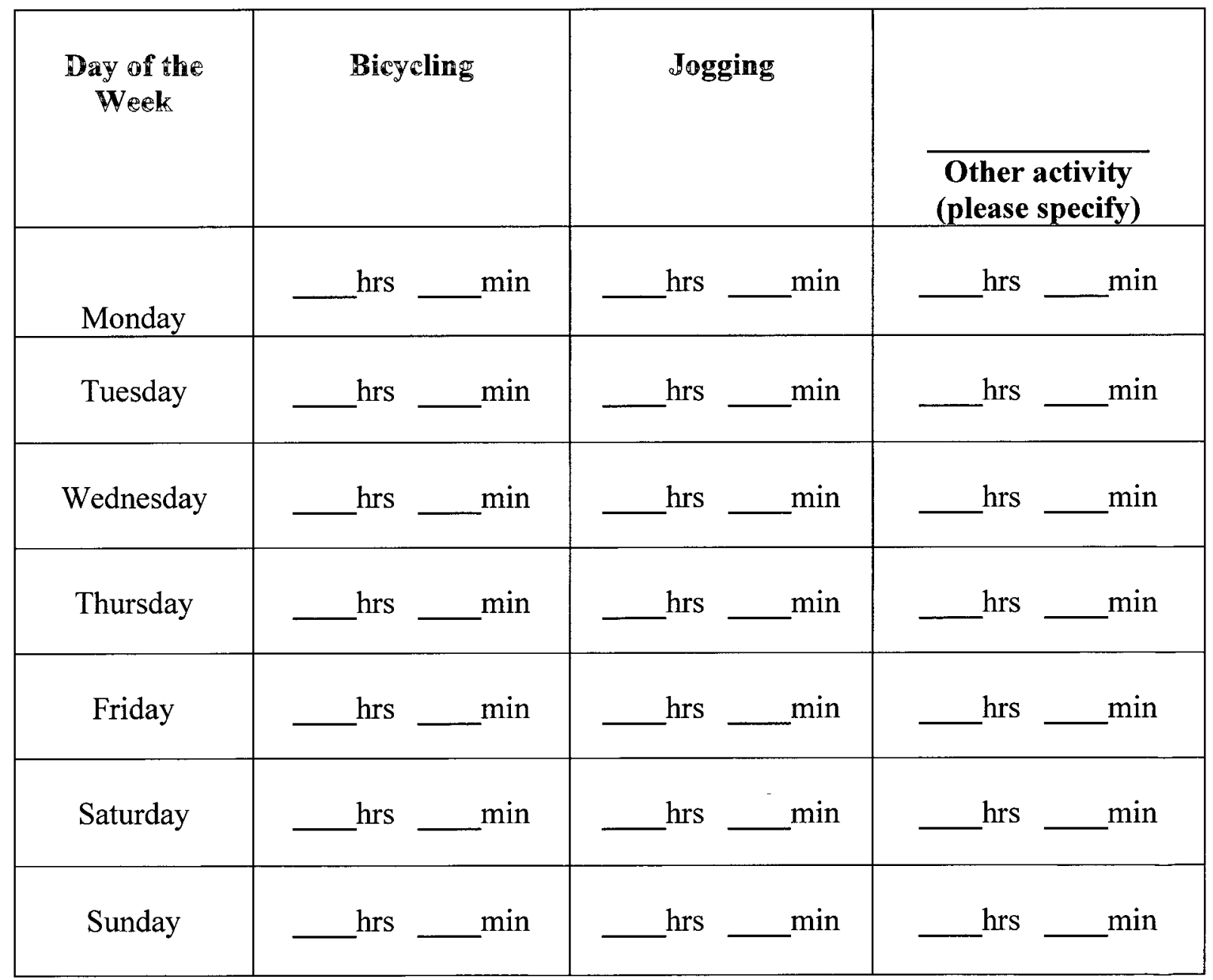




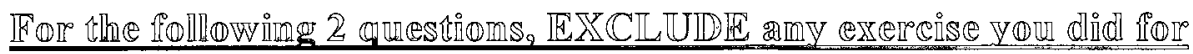

\section{TRANSPORTATION}

\section{(i.e., for the purpose of getting from one location to another).}

5) During the last 7 days, approximately how much time did you spend walking during your free time? Do not include periods in which you walked for less than 10 minutes and, if you are a dog owner, do not include any time spent walking with your dog.

$\begin{array}{lll}\text { Monday } & \overline{\text { Hours }} & \overline{\text { Minutes }} \\ \text { Tuesday } & \overline{\text { Hours }} & \overline{\text { Minutes }} \\ \text { Wednesday } & \overline{\text { Hours }} & \overline{\text { Minutes }} \\ \text { Thursday } & \overline{\text { Hours }} & \overline{\text { Minutes }} \\ \text { Friday } & \overline{\text { Hours }} & \overline{\text { Minutes }} \\ \text { Saturday } & \overline{\text { Hours }} & \overline{\text { Minutes }} \\ \text { Sunday } & \overline{\text { Hours }} & \overline{\text { Minutes }}\end{array}$

6) In you walked during your free time in the past 7 days, in general, how fast was your pace (tick one)?

Slow pace

Moderate pace

Fast/brisk pace 
7) Please list any type of physical activity other than walking (e.g॰ jogging, soccer, yoga) that you did during your leisure time in the last 7 days and indicate the total time you spent on that physical activity. Only include physical activities that you did for periods of at least 10 minutes each time. If you are a dog owner, do not include physical activities that you did with your dog.

\section{Name of physical activity}

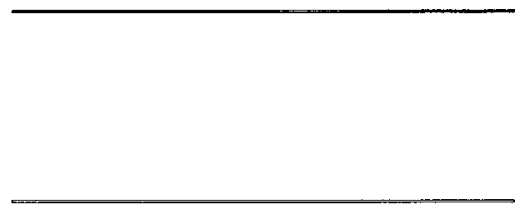

Total time spent on the activity in the last 7 days (excluding sessions less than 10 minutes)

\begin{tabular}{ll}
$\overline{\text { Hours }}$ & $\overline{\text { Minutes }}$ \\
\hline$\overline{\text { Hours }}$ & $\overline{\text { Minutes }}$ \\
$\overline{\text { Hours }}$ & $\overline{\text { Minutes }}$ \\
$\overline{\text { Hours }}$ & $\overline{\text { Minutes }}$ \\
& \\
$\overline{\text { Hours }}$ & $\overline{\text { Minutes }}$
\end{tabular}




\section{Additional Physical Health Questioms}

1. What is your height (in either)

$\overline{\text { Centimeters }}$ or $\quad$ Feet $\quad$ Inches

2. What is your weight (in either)

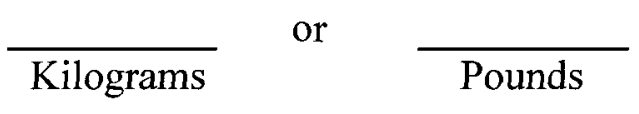

3. In the past yeare, how many times have you visited any type of medical doctor?

_times in the past year

4. How many types of prescription medications have you taken in the past month (excluding birth control pills)? prescription medications in the past month

5. Overall, how would you describe your current health? (circle one):

$\begin{array}{llll}\text { Poor } & \text { Fair } & \text { Good } & \text { Very good }\end{array}$




\section{Center for Epidemiologic Studies-Depression Scale (CES-D)}

Below is a list of the ways you might have felt or behaved. Please indicate how often you have felt or behaved this way during the past week:

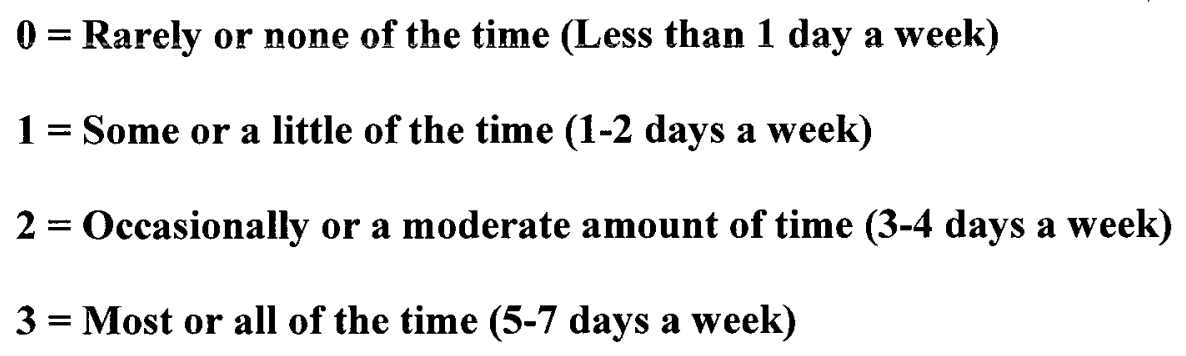

\section{During the past week}

1. I was bothered by things that usually don't bother me. $\begin{array}{lllll}0 & 1 & 2 & 3\end{array}$

2. I did not feel like eating; my appetite was poor. $\quad \begin{array}{llllll}0 & 1 & 2 & 3\end{array}$

3. I felt that I could not shake off the blues even with $\begin{array}{llllll}0 & 1 & 2 & 3\end{array}$ help from my family or friends.

4. I felt that I was just as good as other people.

5. I had trouble keeping my mind on what I was doing. $\begin{array}{llllll}0 & 1 & 2 & 3\end{array}$

$\begin{array}{llllll}\text { 6. I felt depressed. } & 0 & 1 & 2 & 3\end{array}$

$\begin{array}{llllll}\text { 7. I felt that everything I did was an effort. } & 0 & 1 & 2 & 3\end{array}$

$\begin{array}{llllll}\text { 8. I felt hopeful about the future. } & 0 & 1 & 2 & 3\end{array}$

9. I thought my life had been a failure. $\quad \begin{array}{llllll}0 & 1 & 2 & 3\end{array}$

10. I felt fearful. $\quad \begin{array}{lllll}0 & 1 & 2 & 3\end{array}$

$\begin{array}{lllll}\text { 11. My sleep was restless. } & 0 & 1 & 2 & 3\end{array}$

12. I was happy. $\quad \begin{array}{lllll}0 & 1 & 2 & 3\end{array}$ 


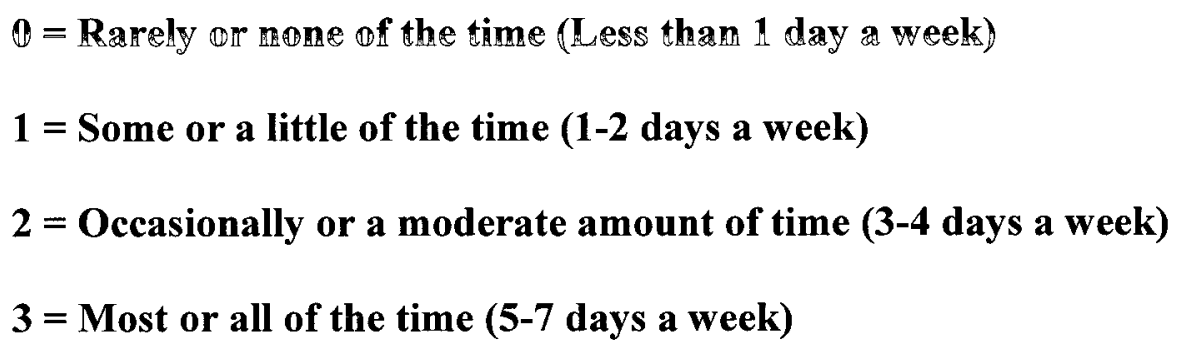

\section{During the past week}

13. I talked less than usual.

14. I felt lonely.

15. People were unfriendly.

16. I enjoyed life.

17. I had crying spells.

18. I felt sad.

19. I felt that people disliked me.

20. I could not get "going".

\section{$\underline{\text { Answer (circle) }}$}

$\begin{array}{llll}0 & 1 & 2 & 3 \\ 0 & 1 & 2 & 3 \\ 0 & 1 & 2 & 3 \\ 0 & 1 & 2 & 3 \\ 0 & 1 & 2 & 3 \\ 0 & 1 & 2 & 3 \\ 0 & 1 & 2 & 3 \\ 0 & 1 & 2 & 3\end{array}$


The Positive and Negative Affect Scales (PANAS)

Listed below are a number of words that describe different feelings and emotions. For each, please pick a number from the following scale to indicate the extent to which you feel this way, IN GENERAL. That is, how you feel on average.

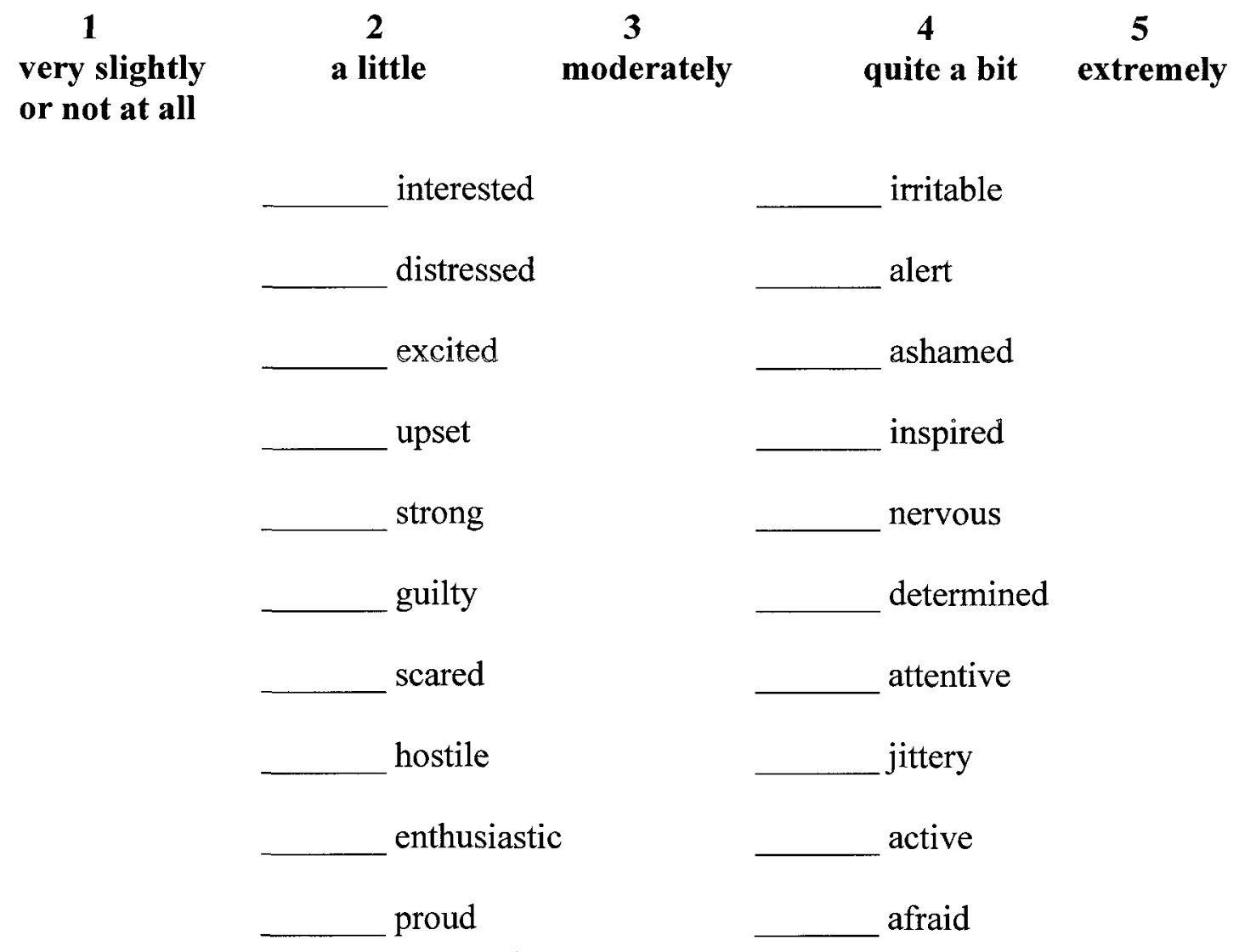




\section{State-Trait Anxiety Inventory (STAI Form Y-2) \\ (C) 1968,1977 by Charles D. Spielberger.}

Five items reproduced with permission of the publisher, Mindgarden, Inc.

A number of statements that people have used to describe themselves are given below.

Read each statement and then circle the number that best describes how you generally feel.

$$
\begin{aligned}
& 1=\text { Almost never } \\
& 2=\text { Sometimes } \\
& 3=\text { Often } \\
& 4=\text { Almost always }
\end{aligned}
$$

\section{$\underline{\text { Answer (circle) }}$}

1. I feel pleasant

$\begin{array}{llll}1 & 2 & 3 & 4\end{array}$

2. I feel nervous and restless

$\begin{array}{llll}1 & 2 & 3 & 4\end{array}$

3. I feel satisfied with myself

$\begin{array}{llll}1 & 2 & 3 & 4\end{array}$

4. I wish I could be as happy as others seem to be

$\begin{array}{llll}1 & 2 & 3 & 4\end{array}$

5. I feel like a failure

$\begin{array}{llll}1 & 2 & 3 & 4\end{array}$




\section{Perceived Stress Scale (PSS)}

Listed below are various feelings and thoughts that people may experience. For each, please choose the best number to describe how often you have experienced each thought or feeling during the last month:

$$
\begin{aligned}
& \mathbf{0}=\text { Never } \\
& 1=\text { Almost never } \\
& 2=\text { Sometimes } \\
& 3=\text { Fairly often } \\
& 4=\text { Very often }
\end{aligned}
$$

\section{In the past month, how often have you}

1. been upset because of something that happened unexpectedly?

2. felt that you were unable to control the important things in your life? $\quad \begin{array}{lllll}0 & 1 & 2 & 3 & 4\end{array}$

3. felt nervous and "stressed"?

4. dealt successfully with irritating life hassles?

5. felt that you were effectively coping with important changes that were occurring in your life?

6. felt confident about your ability to handle your personal problems?

7. felt that things were going your way?

8. found that you could not cope with all the things that you had to do?

9. been able to control irritations in your life? $\begin{array}{lllll}0 & 1 & 2 & 3 & 4\end{array}$

$\begin{array}{lllll}0 & 1 & 2 & 3 & 4\end{array}$

\section{$\underline{\text { Answer (circle) }}$}

$\begin{array}{lllll}0 & 1 & 2 & 3 & 4\end{array}$

$\begin{array}{lllll}0 & 1 & 2 & 3 & 4\end{array}$

$\begin{array}{lllll}0 & 1 & 2 & 3 & 4\end{array}$

$\begin{array}{lllll}0 & 1 & 2 & 3 & 4\end{array}$

$\begin{array}{lllll}0 & 1 & 2 & 3 & 4\end{array}$

$\begin{array}{lllll}0 & 1 & 2 & 3 & 4\end{array}$ 


$$
\begin{aligned}
& 0=\text { Never } \\
& 1=\text { Almost never } \\
& 2=\text { Sometimes } \\
& 3=\text { Fairly often } \\
& 4=\text { Very often }
\end{aligned}
$$

\section{In the past month, how often have you}

10. felt that you were on top of things?

11. been angered because of things that happened that were outside of your control?

12. found yourself thinking about things that you have to accomplish?

13. been able to control the way you spend your time?

14. felt difficulties were piling up so high that you could not overcome them?

\section{$\underline{\text { Answer (circle) }}$}

$\begin{array}{lllll}0 & 1 & 2 & 3 & 4\end{array}$

$\begin{array}{lllll}0 & 1 & 2 & 3 & 4\end{array}$

$\begin{array}{lllll}0 & 1 & 2 & 3 & 4\end{array}$

$\begin{array}{lllll}0 & 1 & 2 & 3 & 4\end{array}$

$\begin{array}{lllll}0 & 1 & 2 & 3 & 4\end{array}$

In the past month, have you experienced a traumatic or extremely distressing event, such as a death in you family? a) No

b) Yes If yes, please describe 


\section{Marlowe-Cred me Social Desirabiltiy Scale}

Listed below are a number of statements concerning personal attitudes and traits. Please read each item and decide whether the statement is true or false as it applies to you. For each item, please select TRUE or FALSE.

1. It is sometimes hard for me to go on with my work if I am not encouraged.

2. I sometimes feel resentful when I don't get my way.

3. On a few occasions, I have given up doing something because I thought too little of my ability.

4. There have been times when I felt like rebelling against people in authority even though $I \mathrm{knew}$ they were right.

5. No matter who I'm talking to, I'm always a good listener.

True False

6. There have been occasions when I took advantage of someone.

True False

7. I'm always willing to admit to it when I make a mistake.

True False

8. I sometimes try to get even rather than forgive and forget.

True False

9. I am always courteous, even to people who are disagreeable.

True False

10. I have never been irked when people expressed ideas very

True False different from my own.

11. There have been times when I was quite jealous of the good fortune of others.

True False

12. I am sometimes irritated by people who ask favors of me.

True False

13. I have never deliberately said something that hurt someone's feelings. True False 


\section{Dog Ownership and Dog Walking}

1. Do you own a dog(s)? (circle) Yes / No

1a. If No, did you own a dog within the last 6 months? (circle) Yes / No

2. Do you own a cat(s)? (circle) Yes / No

If you indicated that you do not currently own a dog you have finished the questionnaire. Please go to the last page of the questionnaire.

If you indicated that you currently do own a dog, please continue answering the rest of the questionnaire.

\section{Questions for Dog Owners}

For each of the following questions, please circle the number that best describes how you feel:

$$
\begin{aligned}
& 1=\text { Strongly agree } \\
& 2=\text { Agree } \\
& 3=\text { Neutal } \\
& 4=\text { Disagree } \\
& 5=\text { Strongly disagree }
\end{aligned}
$$

\section{Answer (circle)}

1. My dog gives me something to care for. $\begin{array}{llllll}1 & 2 & 3 & 4 & 5\end{array}$

2. My dog is a source of companionship. $\begin{array}{lllllll}1 & 2 & 3 & 4 & 5\end{array}$

$\begin{array}{lllllll}\text { 3. My dog is a loyal companion. } & 1 & 2 & 3 & 4 & 5\end{array}$

4. When I am stressed, my dog is a source $\begin{array}{lllllll}1 & 2 & 3 & 4 & 5\end{array}$ of comfort to me.

5. My dog does not make me feel loved. $\begin{array}{lllllll}1 & 2 & 3 & 4 & 5\end{array}$

6. My dog is a source of non-judgmental $\quad \begin{array}{lllllll}1 & 2 & 3 & 4 & 5\end{array}$ support. 


$$
\begin{aligned}
& \mathbb{1}=\text { Stromgly פgree } \\
& 2=\text { Agree } \\
& 3=\text { Neutal } \\
& 4=\text { Disagree } \\
& 5=\text { Strongly disagree }
\end{aligned}
$$

\section{(circle)}

7. Petting my dog does not relax me. $\quad \begin{array}{lllllll}1 & 2 & 3 & 4 & 5\end{array}$

8. Being with my dog helps me forget $\quad \begin{array}{llllllll}1 & 2 & 3 & 4 & 5\end{array}$ my problems.

9. Caring for my dog makes me feel useful. $\begin{array}{lllllll}1 & 2 & 3 & 4 & 5\end{array}$

10. My dog is a source of social support $\quad \begin{array}{llllll}1 & 2 & 3 & 4 & 5\end{array}$ to me.

$\begin{array}{lllllll}\text { 11. My dog makes me laugh. } & 1 & 2 & 3 & 4 & 5\end{array}$

12. When things go wrong, my dog is there. $\begin{array}{lllllll}1 & 2 & 3 & 4 & 5\end{array}$ for me.

$\begin{array}{lllllll}\text { 13. My dog makes me feel safe. } & 1 & 2 & 3 & 4 & 5\end{array}$

14. My dog is not a source of entertainment. $\begin{array}{lllllll}1 & 2 & 3 & 4 & 5\end{array}$

15. Hugging my dog makes me feel good. $\begin{array}{llllllll}1 & 2 & 3 & 4 & 5\end{array}$

$\begin{array}{lllllll}\text { 16. My dog gives me affection. } & 1 & 2 & 3 & 4 & 5\end{array}$

17. I am a parent to my dog. $\quad \begin{array}{llllll}1 & 2 & 3 & 4 & 5\end{array}$

18. My dog keeps me from being lonely. $\begin{array}{lllllll}1 & 2 & 3 & 4 & 5\end{array}$

19. My dog is not a good watch dog. $\quad \begin{array}{llllllll}1 & -2 & 3 & 4 & 5\end{array}$ 


\section{Pet Attachnemet Sedle}

For each of the following statements, please circle the best answer:

1. Would you say owning a pet has helped your health?

$\begin{array}{cc}1 & 0 \\ \text { Yes } & \text { No/Maybe }\end{array}$

2. To what extent do you agree with the statement: "No family is complete until there is a pet in the home."

$\begin{array}{llll}0 & 1 & 2 & 3\end{array}$ $\begin{array}{llll}\text { Disagree strongly } & \text { Disagree } & \text { Agree } & \text { Agree strongly }\end{array}$

3. How often are your feelings toward people affected by the way they react to your pets?

$\begin{array}{ccccc}0 & 1 & 2 & 3 & 4 \\ \text { Never } & \text { Seldom } & \text { Occasionally } & \text { Often } & \text { Always }\end{array}$

4. How often do you take pets along when you visit friends or relatives?

$\begin{array}{ccccc}0 & 1 & 2 & 3 & 4 \\ \text { Never } & \text { Seldom } & \text { Occasionally } & \text { Often } & \text { Always }\end{array}$

5. To what extent do you agree with the statement: "Pets should have the same rights and privileges as family members."
0
1
Disagree strongly
Disagree
2
Agree
3 Agree strongly

6. Do you keep a picture of your pet in your wallet or on display at your home or office?

$\begin{array}{cc}1 & 0 \\ \text { Yes } & \text { No/Maybe }\end{array}$


7. To what extent do you agree with the statement: "I like my pet because he/she is more loyal to me than the people in my life."
0
1
2
3
Disagree strongly
Disagree
Agree
Agree strongly

8. To what extent do you feel that your pet is a part of your family?

$\begin{array}{ccccc}0 & 1 & 2 & 3 & 4 \\ \text { Not at all } & \text { Not much } & \text { A little } & \text { Quite a lot } & \text { Very much }\end{array}$




\section{Dog Owners}

Please answer the following questions:

1. How long have you had your dog? If you own more than one dog, answer with respect to the dog you have had for the longest time.

$$
\overline{\text { Years }} \overline{\text { Months }}
$$

2. Do you walk your dog (tick one)?

Yes

No $\quad \rightarrow$

If you answered 'No,' you do not walk your dog, you have finished the questionnaire. Please go to the last page of the questionnaire.

If you answered ${ }^{6}$ Yes, ${ }^{9}$ you do walk your dog, please answer the remaining questions:

\section{Questions for Dog Walkers Only}

1. When you take your dog out for a walk, how long does it usually last (tick one)?

Less than 10 minutes

10 or more minutes 
2. For the following question, please indicate how much time you spent walking your dog in the past 7 days. Do not include walks that lasted less than 10 minutes or periods when you were standing still.

Monday

$$
\overline{\text { Hours }} \overline{\text { Minutes }}
$$

Tuesday

$$
\overline{\text { Hours }} \overline{\text { Minutes }}
$$

Wednesday

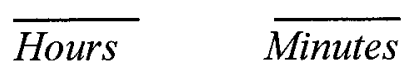

Thursday

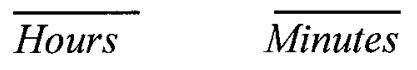

Friday

$$
\overline{\text { Howrs }} \overline{\text { Minutes }}
$$

Saturday

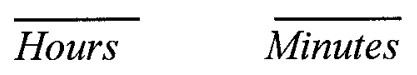

Sunday

$\overline{\text { Hours }} \overline{\text { Minutes }}$

3. In general, how fast did you walk with your dog during the past 7 days (tick one)?

$\begin{array}{ll}\text { Slow pace } & \\ \text { Moderate pace } & \\ \text { Fast/brisk pace }\end{array}$

4. Do you jog with your dog? (circle) Yes / No

4a. If you circled YES, how much time did you spend jogging with your dog in the past week (only include jogging sessions that lasted at least 10 minutes)?

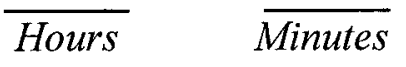


Thamk you for taking the time to complete this questionmaire? If you have any feedback for us, please provide it in the box below: 